\title{
Electron Beam Irradiation as a General Approach for the Rapid Synthesis of Covalent Organic Frameworks under Ambient Conditions
}

Mingxing Zhang ${ }^{1,2,3 *}$, Junchang Chen ${ }^{1 *}$, Shitong Zhang ${ }^{1 \ddagger}$, Xiaoqi Zhou ${ }^{4}$, Linwei He ${ }^{1}$, Matthew V. Sheridan ${ }^{1}$, Mengjia Yuan ${ }^{1}$, Maojiang Zhang ${ }^{2}$, Long Chen ${ }^{1}$, Xing Dai ${ }^{1}$, Fuyin $\mathrm{Ma}^{1}$, Jingdong Wang ${ }^{1}$, Jiangtao $\mathrm{Hu}^{2}$, Guozhong $\mathrm{Wu}^{2}$, Xueqian Kong ${ }^{4}$, Ruhong Zhou ${ }^{1}$, Thomas E. Albrecht-Schmitt, ${ }^{5}$ Zhifang Chai ${ }^{1}$, Shuao Wang ${ }^{1}$ *

${ }^{1}$ State Key Laboratory of Radiation Medicine and Protection, School for Radiological and

Interdisciplinary Sciences (RAD-X) and Collaborative Innovation Center of Medicine of Jiangsu Higher Education Institutions, Soochow University, Suzhou 215123, China

${ }^{2}$ CAS Center for Excellence on TMSR Energy System, Shanghai Institute of Applied Physics, No. 2019 Jialuo Road, Jiading District, Shanghai 201800, China

${ }^{3}$ University of Chinese Academy of Sciences, Beijing 100049, China

${ }^{4}$ Department of Chemistry, Zhejiang University, Hangzhou 310027, China

${ }^{5}$ Department of Chemistry and Biochemistry, Florida State University, 95 Chieftain Way, Tallahassee, Florida 32306, United States

$\$$ These authors contributed equally.

*Correspondence to: shuaowang@ suda.edu.cn (Shuao Wang) 


\section{Table of contents}

Section S1. Materials and instrumentation

Section S2. Synthesis and characterizations of EB-COF-1

Section S3. EB-COF-1 synthesized at different absorbed dose: synthesis and characterizations

Section S4. Theoretical calculations

Section S5. General nature for the synthesis of COFs 


\section{Section S1. Materials and instrumentation}

\section{Materials}

2,4,6-tris(4-formylphenoxy)-1,3,5-triazine (98\%), 2,4,6-tris(4-aminophenyl)-1,3,5-triazine (98\%), 3,3'-dihydroxybenzidine (98\%), 1,3,5-tris(4-aminophenyl)benzene (98\%), 1,3,5-triformylbenzene (98\%), 2,4,6-tris-(4-aminophenoxy)-1,3,5-triazine (98\%), 2,5-dimethoxyterephthalaldehyde (98\%), 2,2'-bipyridyl-5,5'-dialdehyde (98\%), 2,4,6-tris(4-formylphenyl)-1,3,5-triazine (98\%), and 1,4-phthalaldehyde were purchased from Jilin Chinese Academy of Sciences - Yanshen Technology Co., Ltd. 1,4-Diaminobenzene, 4,4'-diaminobiphenyl, and 4,4'-biphenyldicarboxaldehyde were purchased from Aladdin Co., Ltd. 3,3'-Dimethylbiphenyl-4,4'-diamine was purchased from Xiya Chemical Technology Co., Ltd. 3,3'-Dimethoxybenzidine was purchased from TCI Co., Ltd. 1,3,5-Tris(4-formylphenyl)benzene was purchased from Chemsoon Co., Ltd. 2,5-Dihydroxy-1,4-benzenedicarboxaldehyde was purchased from Beijing HWRK Chem Co., Ltd. Mesitylene was purchased from J\&K Scientific Ltd. 1,2-Dichlorobenzene was purchased from Shanghai Macklin Biochemical Co., Ltd. Butyl alcohol (AR), 1,4-dioxane (AR), tetrahydrofuran (AR), ethanol absolute (AR), and acetic acid (98\%) were purchased from Chinasun Specialty Products Co., Ltd. All reagents and solvents were used without further purification.

\section{Instrumentation}

Electron irradiation accelerator device. The energy of electron beam flow is $1.5 \mathrm{MeV}$, the intensity of electron beam is $1.4 \mathrm{~mA}$, and the power of the electron accelerator is $80 \mathrm{~kW}$.

Fourier transform infrared spectroscopy (FT-IR). All FT-IR spectra of the monomers and as-prepared COFs were recorded on a Thermo Nicolet iS50 spectrometer in a range of 400-4000 $\mathrm{cm}^{-1}$ at a resolution of $4 \mathrm{~cm}^{-1}$.

Solid-state nuclear magnetic resonance (SSNMR). All ${ }^{13} \mathrm{C}$ cross-polarization magic angle spinning (CP/MAS) solid state nuclear magnetic resonance (NMR) spectra of the as-prepared COFs were recorded on a AVANCEIII/WB-400 instrument at the Larmor frequency $\left(v_{0}\right)$ of $101 \mathrm{MHz}$.

X-ray photoelectron spectroscopy (XPS). The XPS spectra of the as-prepared COFs were measured using a Thermo Scientific ESCALAB 250 XI instrument to analyze the chemical states.

Field-emission scanning electron microscopy (FE-SEM). All SEM images of the as-prepared COFs were observed under the vacuum using a field-emission scan electron microscope (FE-SEM, Merlin Compact, Zeiss) at a $10.0 \mathrm{kV}$ acceleration voltage and all samples were coated with gold to improve the electronic conductivity.

Thermogravimetric analysis (TGA). The TG curves of the as-prepared COFs were performed on a NETZSCH STA 449F3 Instrument in the range of 30 to $900{ }^{\circ} \mathrm{C}$ with a heating rate of $10{ }^{\circ} \mathrm{C} / \mathrm{min}$ under a $\mathrm{N}_{2}$ atmosphere.

Powder x-ray diffraction (PXRD). The PXRD patterns of the as-prepared COFs were collected on a Bruker D8 Advance diffractometer and measured with $\mathrm{Cu} K \alpha$ radiation $(\lambda=1.54056 \AA)$ with a step size of $0.02^{\circ}$ in $2 \theta$ from $2 / 2.5^{\circ}$ to $30^{\circ}$.

$\mathbf{N}_{2}$ adsorption-desorption analysis. The $\mathrm{N}_{2}$ adsorption-desorption experiments of the as-prepared COFs were conducted on a Micromeritics ASAP 2460 Surface Area and Porosimetry Analyzer at $77 \mathrm{~K}$ by using ultra-high purity $\mathrm{N}_{2}$. All samples were degassed at $150{ }^{\circ} \mathrm{C}$ for $12 \mathrm{~h}$ before the measurements. The surface area was determined using Brunauer-Emmett-Teller (BET) adsorption model. The pore size distribution was calculated by nonlocal density functional theory (NLDFT) method from the 
adsorption isotherm.

\section{Section S2. Synthesis and characterizations of EB-COF-1}

\section{Synthesis of EB-COF-1}

A $3 \mathrm{~mL}$ scintillation vial was charged with 2,4,6-tris-(4-formylphenoxy)-1,3,5-triazine (TPT-CHO, $22.0 \mathrm{mg}, 0.05 \mathrm{mmol}$ ), 1,3,5-tris(4-aminophenyl)trianiline (TAPT, $17.7 \mathrm{mg}, 0.05 \mathrm{mmol}$ ), $0.25 \mathrm{~mL}$ of 1,2-dichlorobenzene and $0.25 \mathrm{~mL}$ of butyl alcohol. After ultrasonicating for $2 \mathrm{~min}, 0.05 \mathrm{~mL}$ of aqueous acetic acid $(6 \mathrm{M})$ was added to the solution. Then the mixture was bulged $\mathrm{N}_{2}$ for 1 min to remove $\mathrm{O}_{2}$ and sealed. After that, the sample was irradiated using electron beam at an absorbed dose rate of 625 Gy/s for $160 \mathrm{~s}$ and the accumulated absorbed dose was $100 \mathrm{kGy}$. The obtained precipitation was successively washed by tetrahydrofuran for two times and by ethanol absolute for two times, and then dried in an oven at $60{ }^{\circ} \mathrm{C}$ for $24 \mathrm{~h}$ to afford a yellow powder in $92 \%$ isolated yield (Scheme 1).

The scheme to show the operation of electron beam irradiation is shown in Figure 1. The sample table is used to place irradiation samples and the irradiation window is used to generate electron beam flows. The distance between the sample table and irradiation window is $20 \mathrm{~cm}$. The effective irradiation area is about $70 \times 80 \mathrm{~cm}^{2}$, which is determined by the irradiation window. The absorbed dose is measured by the dose tablet. In our system, the precursor sample is placed in a scintillation vial and sealed with a thin parafilm. The vial is placed on the sample table under ambient condition. The electron beam flows and penetrates the thin parafilm (the energy and intensity loss during this process is negligible), which vertically irradiates the precursor samples.

The estimated energy consumption for making $100 \mathrm{mg}$ of products via electron beam irradiation is calculated based on the power of the electron accelerator $(80 \mathrm{~kW})$ and the irradiation time $(160 \mathrm{~s})$ to be $1.28 * 10^{7} \mathrm{~J}$. Very impressively, this is about two orders of magnitude lower than that of same amount of products synthesized from the solvothermal method (even with a much poorer crystallinity) of $1.04 * 10^{9} \mathrm{~J}$ (the power of the oven for heating is $4 \mathrm{~kW}$ and the heating time is 3 days).

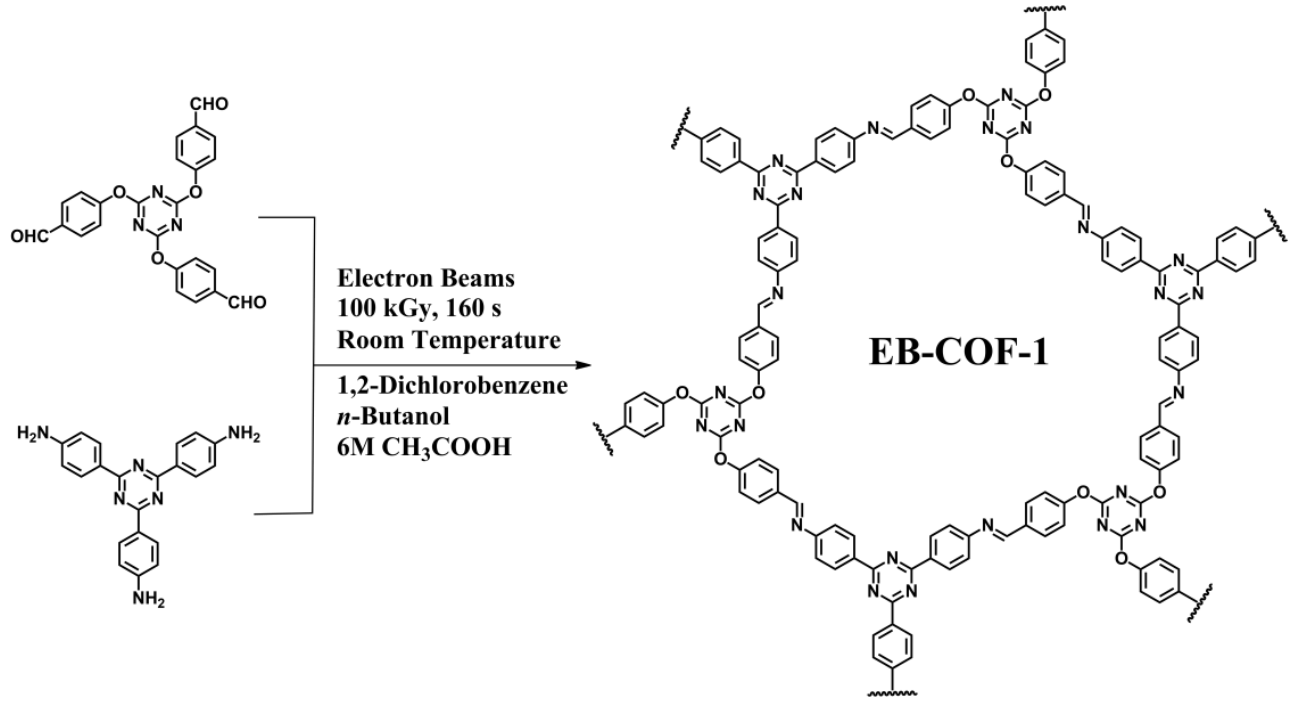

Scheme S1. Molecular structure of EB-COF-1 synthesized from a condensation reaction of TAPT and TPT-CHO 


\section{Characterizations of EB-COF-1}

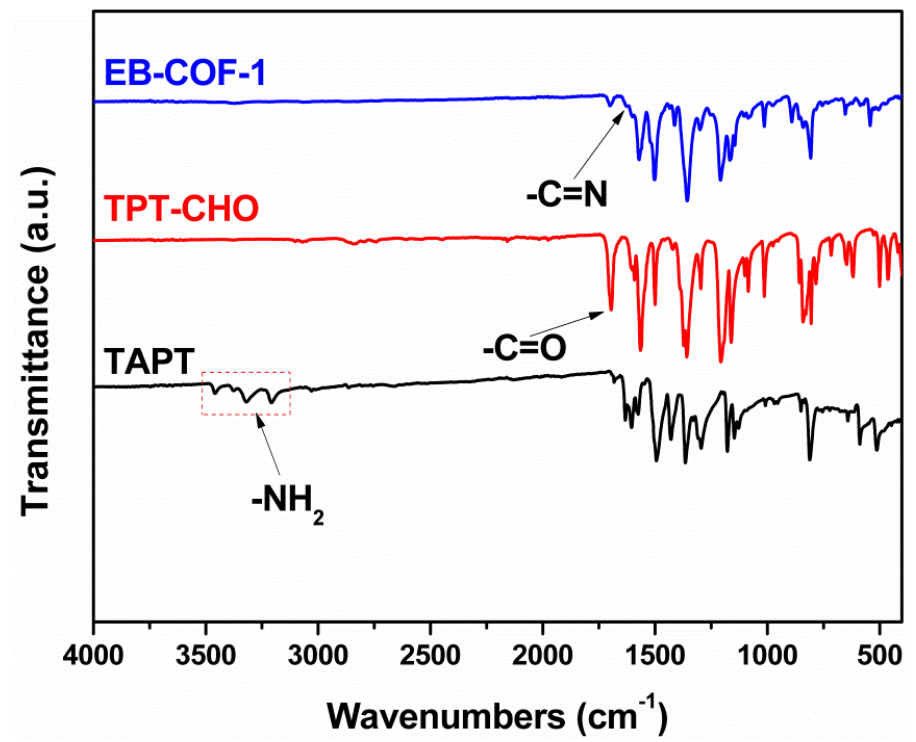

Figure S1. FT-IR spectra of TAPT, TPT-CHO, and EB-COF-1.

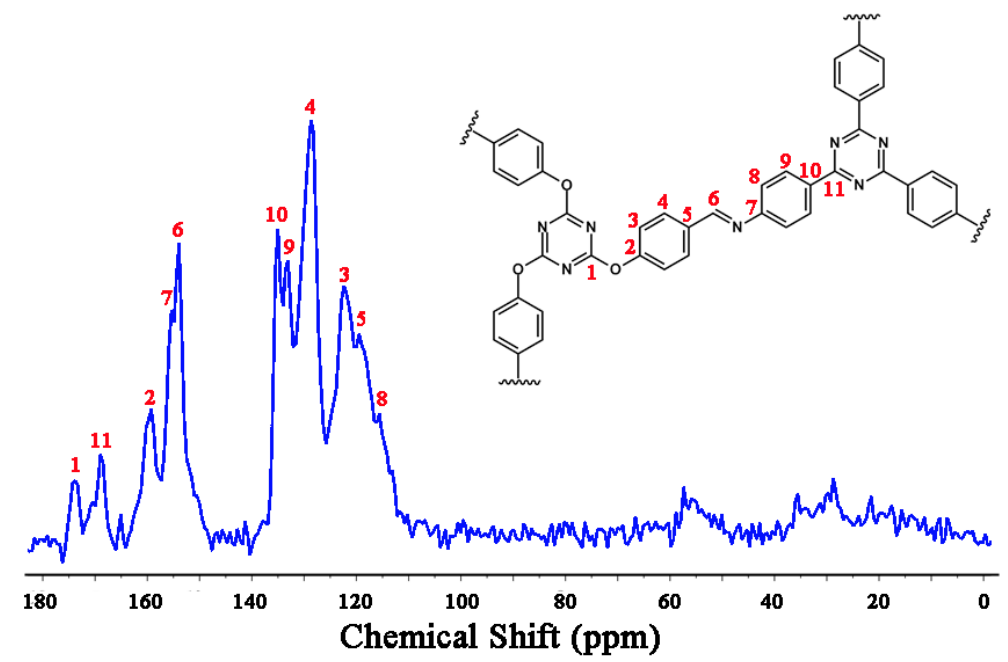

Figure S2. Solid-state ${ }^{13} \mathrm{C}$ NMR spectrum of EB-COF-1. 


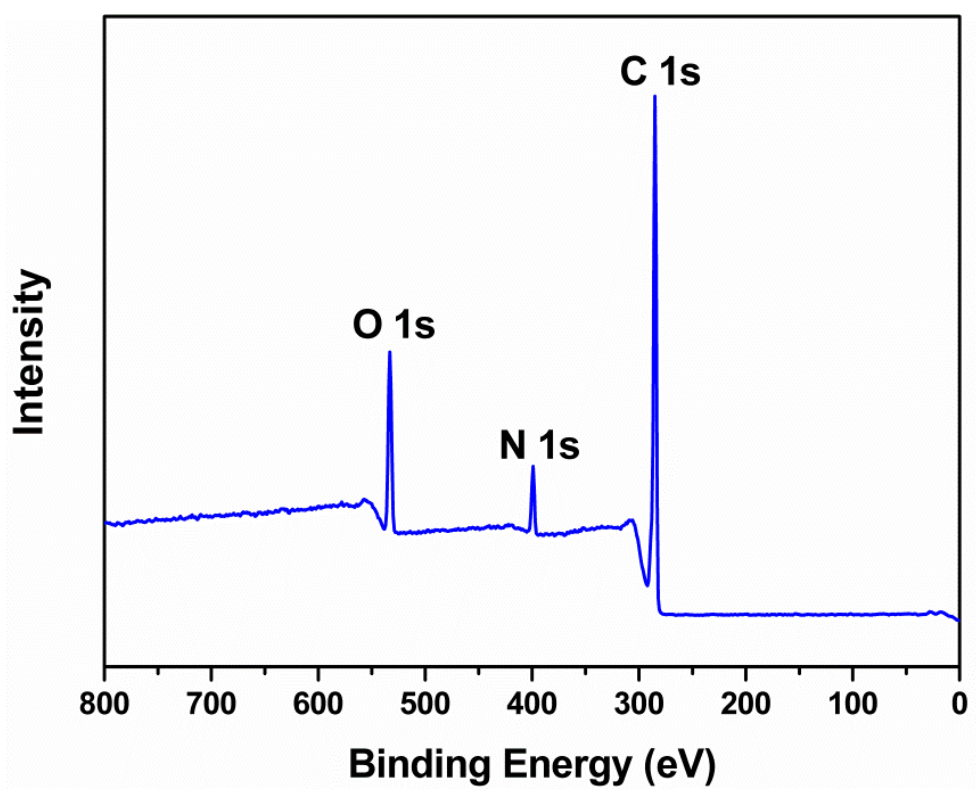

Figure S3. XPS spectrum of EB-COF-1.

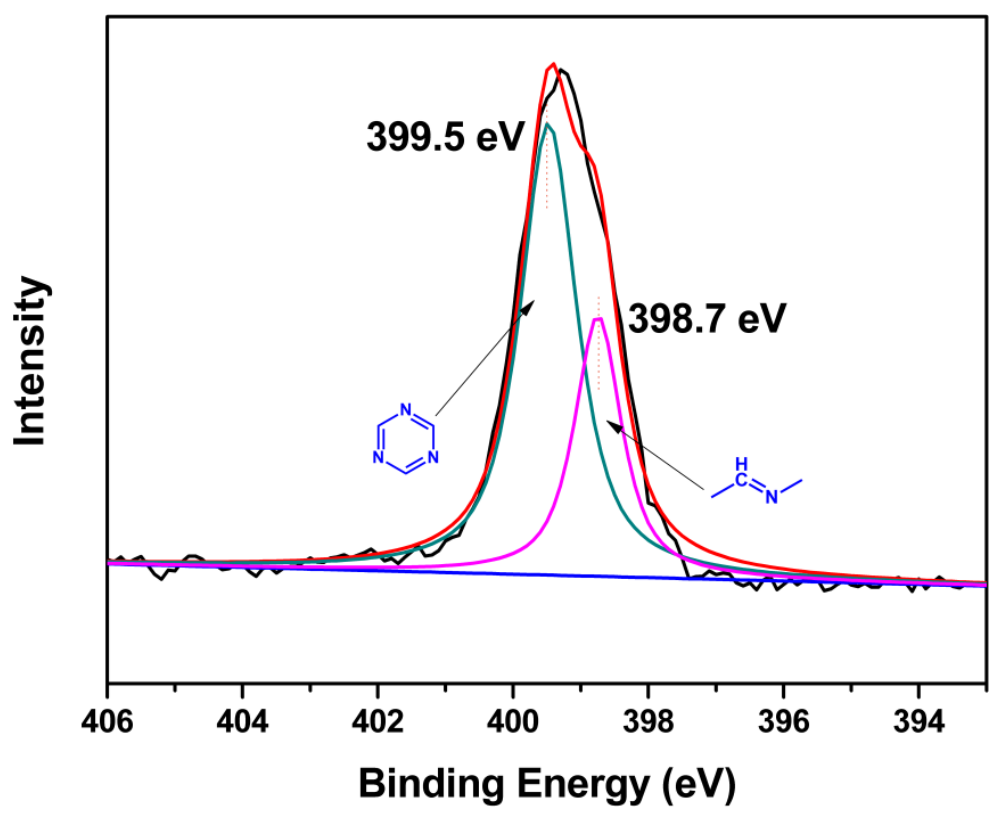

Figure S4. N 1s core level spectra of EB-COF-1. 


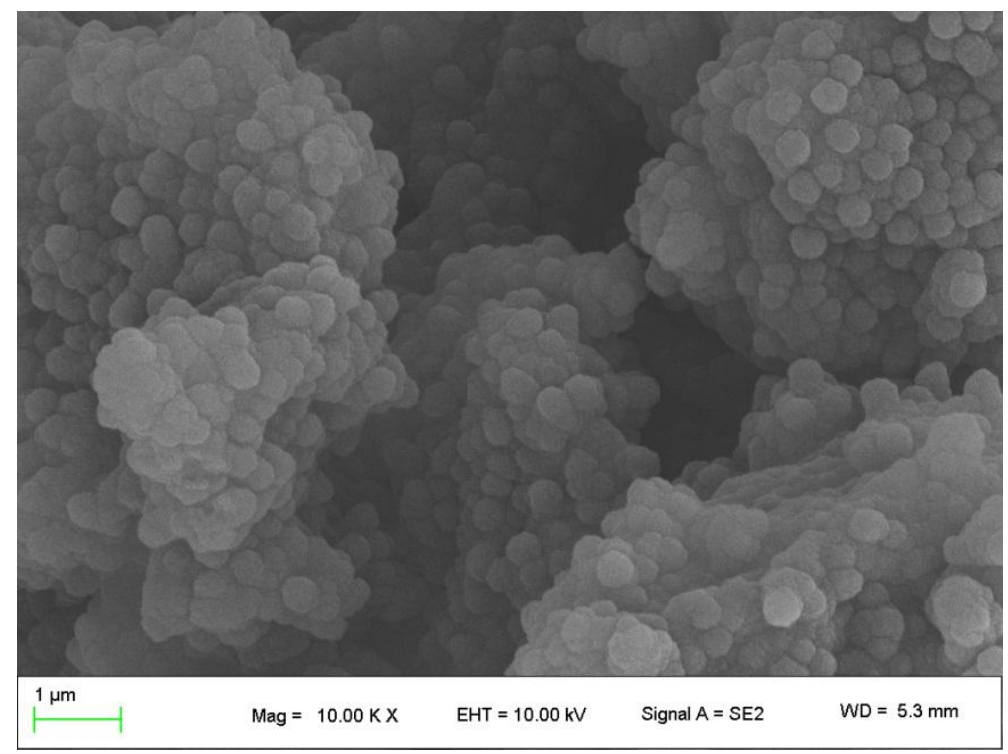

Figure S5. SEM image of EB-COF-1.

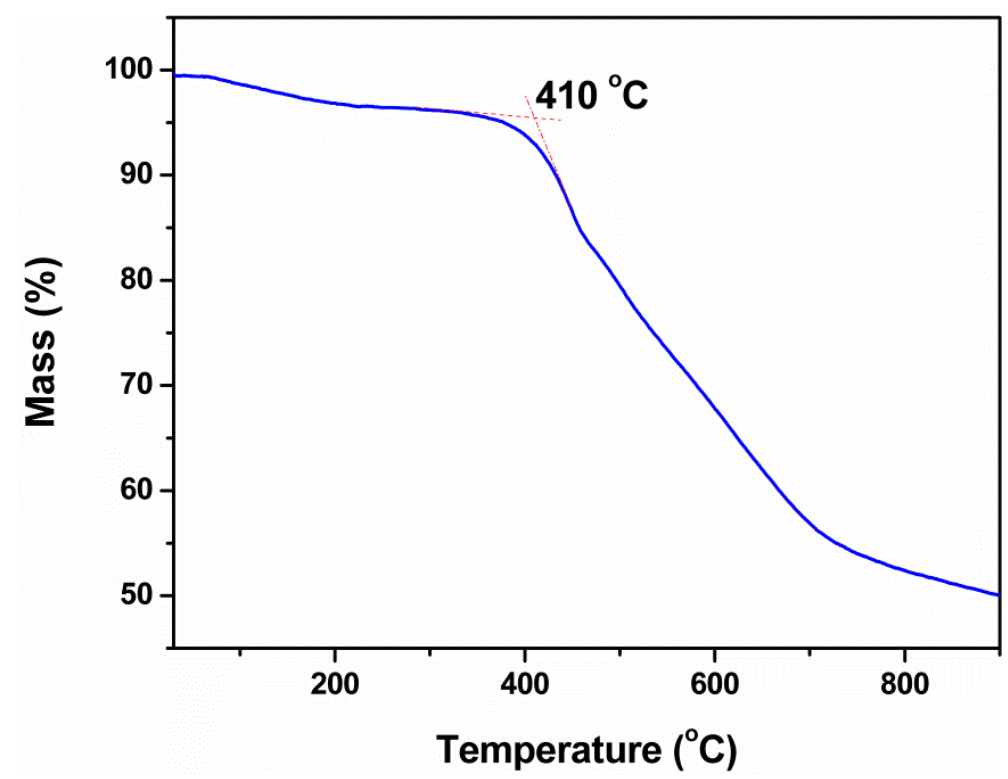

Figure S6. TG curve of EB-COF-1.

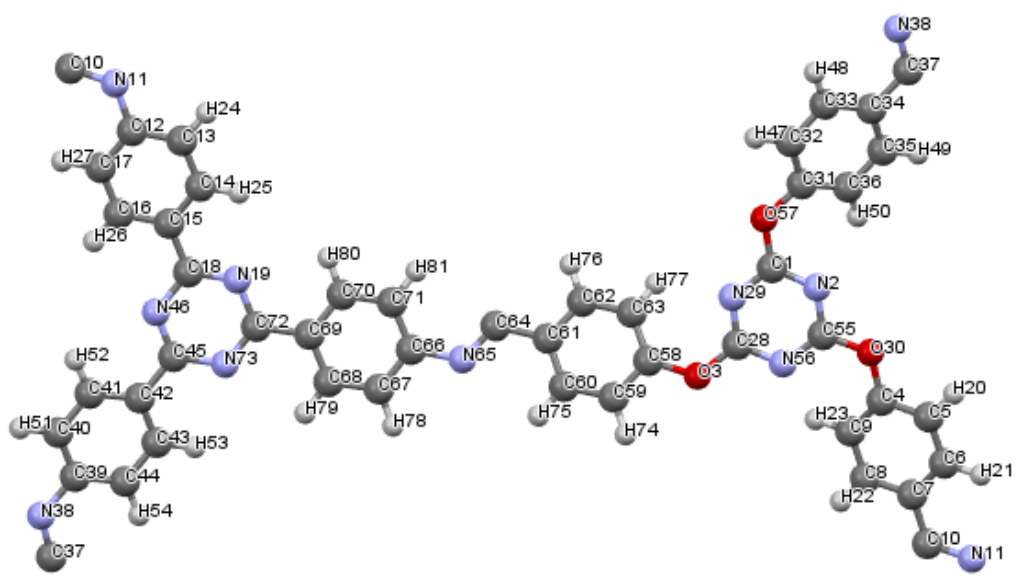

Figure S7. The asymmetric unit of EB-COF-1. 
Table S1. Atomic coordinates for EB-COF-1.

\begin{tabular}{|c|c|c|c|}
\hline Atom & $\mathrm{x} / \mathrm{a}$ & $\mathrm{y} / \mathrm{b}$ & $\mathrm{z} / \mathrm{c}$ \\
\hline $\mathrm{C} 1$ & 0.28669 & 0.61366 & 0.51385 \\
\hline $\mathrm{N} 2$ & 0.28085 & 0.66038 & 0.51796 \\
\hline $\mathrm{O} 3$ & 0.44204 & 0.68208 & 0.50988 \\
\hline $\mathrm{C} 4$ & 0.36207 & 0.81709 & 0.49133 \\
\hline $\mathrm{C} 5$ & 0.34854 & 0.85811 & 0.60268 \\
\hline C6 & 0.38836 & 0.91598 & 0.58428 \\
\hline $\mathrm{C} 7$ & 0.44324 & 0.93423 & 0.45444 \\
\hline $\mathrm{C} 8$ & 0.45699 & 0.89373 & 0.336 \\
\hline C9 & 0.41657 & 0.83578 & 0.34538 \\
\hline C10 & 0.48632 & 0.99501 & 0.43365 \\
\hline N11 & 0.47394 & 0.03421 & 0.50596 \\
\hline C12 & 0.51374 & 0.09405 & 0.49409 \\
\hline $\mathrm{C} 13$ & 0.49362 & 0.1318 & 0.5471 \\
\hline C14 & 0.53073 & 0.19042 & 0.5393 \\
\hline C15 & 0.58912 & 0.21254 & 0.48106 \\
\hline C16 & 0.60937 & 0.17456 & 0.42903 \\
\hline C17 & 0.57208 & 0.11587 & 0.43425 \\
\hline C18 & 0.62861 & 0.27474 & 0.47681 \\
\hline N19 & 0.60828 & 0.31119 & 0.47683 \\
\hline H20 & 0.30657 & 0.8449 & 0.70641 \\
\hline H21 & 0.37634 & 0.94628 & 0.67538 \\
\hline $\mathrm{H} 22$ & 0.4986 & 0.90712 & 0.22481 \\
\hline $\mathrm{H} 23$ & 0.42811 & 0.80713 & 0.22263 \\
\hline $\mathrm{H} 24$ & 0.44888 & 0.11566 & 0.59478 \\
\hline $\mathrm{H} 25$ & 0.51367 & 0.21835 & 0.58231 \\
\hline $\mathrm{H} 26$ & 0.65403 & 0.19013 & 0.38228 \\
\hline H27 & 0.58888 & 0.0877 & 0.39288 \\
\hline C28 & 0.38634 & 0.67303 & 0.51385 \\
\hline N29 & 0.33962 & 0.62047 & 0.51796 \\
\hline O30 & 0.31792 & 0.75996 & 0.50988 \\
\hline C31 & 0.18291 & 0.54498 & 0.49133 \\
\hline C32 & 0.14189 & 0.49043 & 0.60268 \\
\hline C33 & 0.08402 & 0.47238 & 0.58428 \\
\hline C34 & 0.06577 & 0.50901 & 0.45444 \\
\hline $\mathrm{C} 35$ & 0.10627 & 0.56326 & 0.336 \\
\hline C36 & 0.16422 & 0.58079 & 0.34538 \\
\hline C37 & 0.00499 & 0.49131 & 0.43365 \\
\hline N38 & 0.96579 & 0.43973 & 0.50596 \\
\hline
\end{tabular}




\begin{tabular}{|c|c|c|c|}
\hline C39 & 0.90595 & 0.41969 & 0.49409 \\
\hline $\mathrm{C} 40$ & 0.8682 & 0.36182 & 0.5471 \\
\hline $\mathrm{C} 41$ & 0.80958 & 0.34031 & 0.5393 \\
\hline $\mathrm{C} 42$ & 0.78746 & 0.37658 & 0.48106 \\
\hline $\mathrm{C} 43$ & 0.82544 & 0.43481 & 0.42903 \\
\hline $\mathrm{C} 44$ & 0.88413 & 0.45621 & 0.43425 \\
\hline $\mathrm{C} 45$ & 0.72526 & 0.35387 & 0.47681 \\
\hline N46 & 0.68881 & 0.29709 & 0.47683 \\
\hline $\mathrm{H} 47$ & 0.1551 & 0.46167 & 0.70641 \\
\hline $\mathrm{H} 48$ & 0.05372 & 0.43006 & 0.67538 \\
\hline H49 & 0.09288 & 0.59148 & 0.22481 \\
\hline $\mathrm{H} 50$ & 0.19287 & 0.62098 & 0.22263 \\
\hline H51 & 0.88434 & 0.33322 & 0.59478 \\
\hline H52 & 0.78165 & 0.29532 & 0.58231 \\
\hline H53 & 0.80987 & 0.4639 & 0.38228 \\
\hline H54 & 0.9123 & 0.50118 & 0.39288 \\
\hline C55 & 0.32697 & 0.71331 & 0.51385 \\
\hline N56 & 0.37953 & 0.71915 & 0.51796 \\
\hline O57 & 0.24004 & 0.55796 & 0.50988 \\
\hline C58 & 0.45502 & 0.63793 & 0.49133 \\
\hline C59 & 0.50957 & 0.65146 & 0.60268 \\
\hline C60 & 0.52762 & 0.61164 & 0.58428 \\
\hline C61 & 0.49099 & 0.55676 & 0.45444 \\
\hline C62 & 0.43674 & 0.54301 & 0.336 \\
\hline C63 & 0.41921 & 0.58343 & 0.34538 \\
\hline C64 & 0.50869 & 0.51368 & 0.43365 \\
\hline N65 & 0.56027 & 0.52606 & 0.50596 \\
\hline C66 & 0.58031 & 0.48626 & 0.49409 \\
\hline C67 & 0.63818 & 0.50638 & 0.5471 \\
\hline C68 & 0.65969 & 0.46927 & 0.5393 \\
\hline C69 & 0.62342 & 0.41088 & 0.48106 \\
\hline C70 & 0.56519 & 0.39063 & 0.42903 \\
\hline C71 & 0.54379 & 0.42792 & 0.43425 \\
\hline $\mathrm{C} 72$ & 0.64613 & 0.37139 & 0.47681 \\
\hline N73 & 0.70291 & 0.39172 & 0.47683 \\
\hline H74 & 0.53833 & 0.69343 & 0.70641 \\
\hline H75 & 0.56994 & 0.62366 & 0.67538 \\
\hline H76 & 0.40852 & 0.5014 & 0.22481 \\
\hline $\mathrm{H} 77$ & 0.37902 & 0.57189 & 0.22263 \\
\hline $\mathrm{H} 78$ & 0.66678 & 0.55112 & 0.59478 \\
\hline
\end{tabular}




\begin{tabular}{llll}
\hline H79 & 0.70468 & 0.48633 & 0.58231 \\
H80 & 0.5361 & 0.34597 & 0.38228 \\
H81 & 0.49882 & 0.41112 & 0.39288 \\
C10 & 0.48632 & -0.00499 & 0.43365 \\
N11 & 0.47394 & 1.03421 & 0.50596 \\
C37 & 1.00499 & 0.49131 & 0.43365 \\
N38 & -0.03421 & 0.43973 & 0.50596 \\
\hline
\end{tabular}

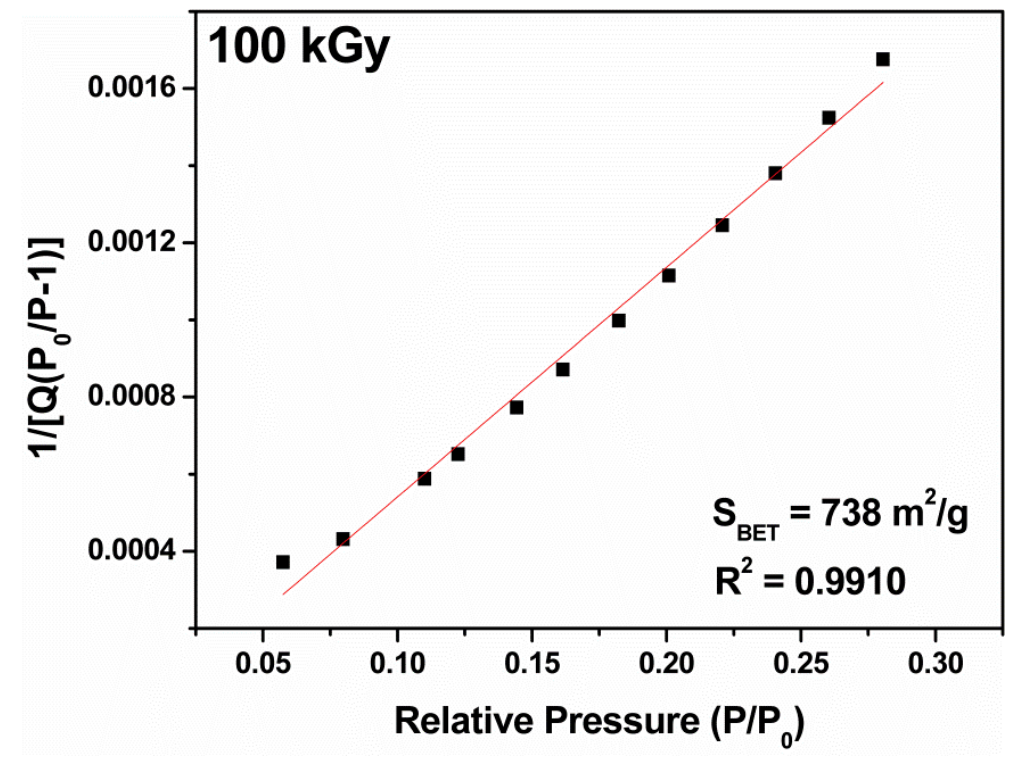

Figure S8. BET plots for EB-COF-1.

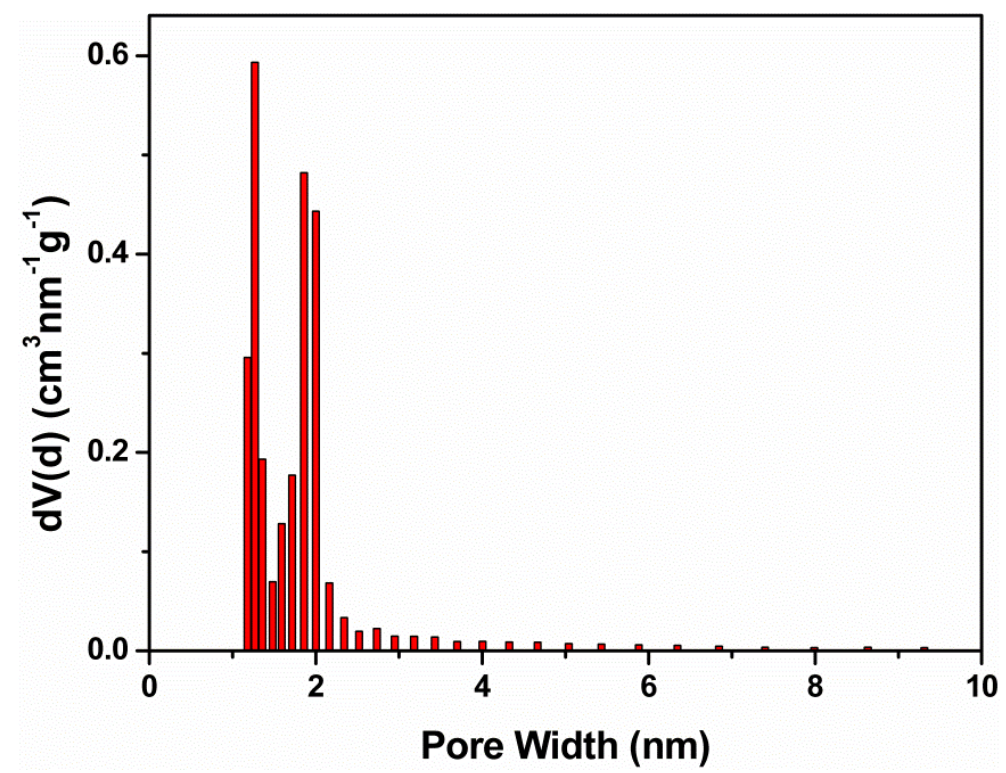

Figure S9. Pore size distribution for EB-COF-1. 


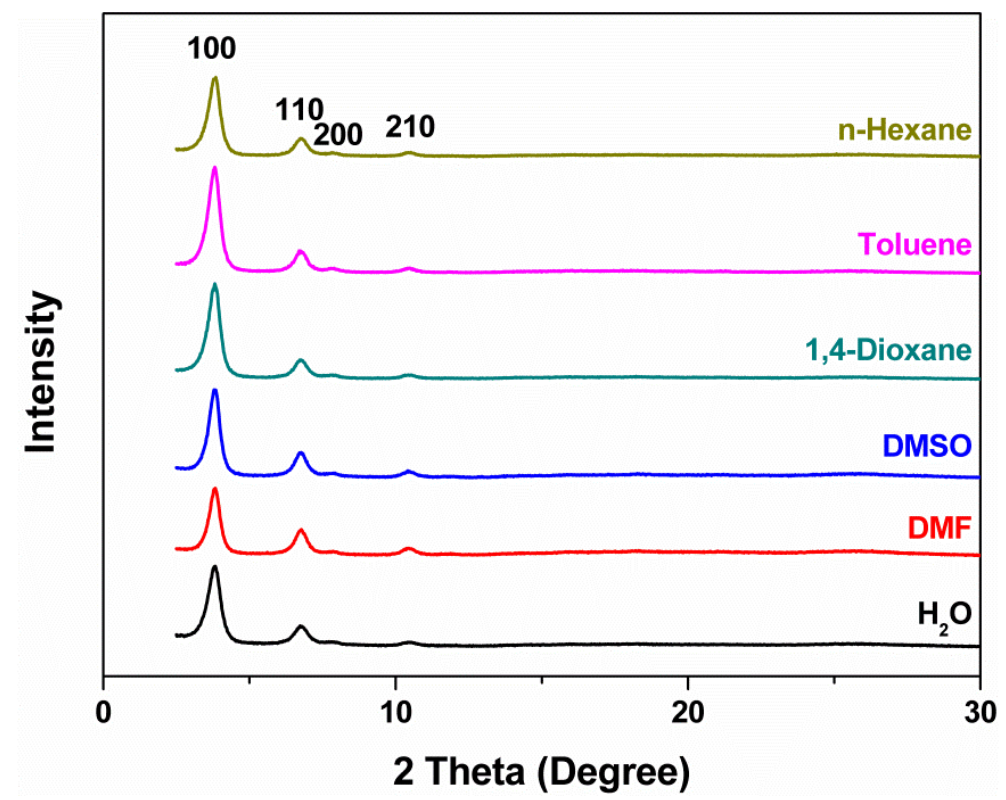

Figure S10. PXRD patterns for EB-COF-1 after immersing in water and organic solvents for 3 days.

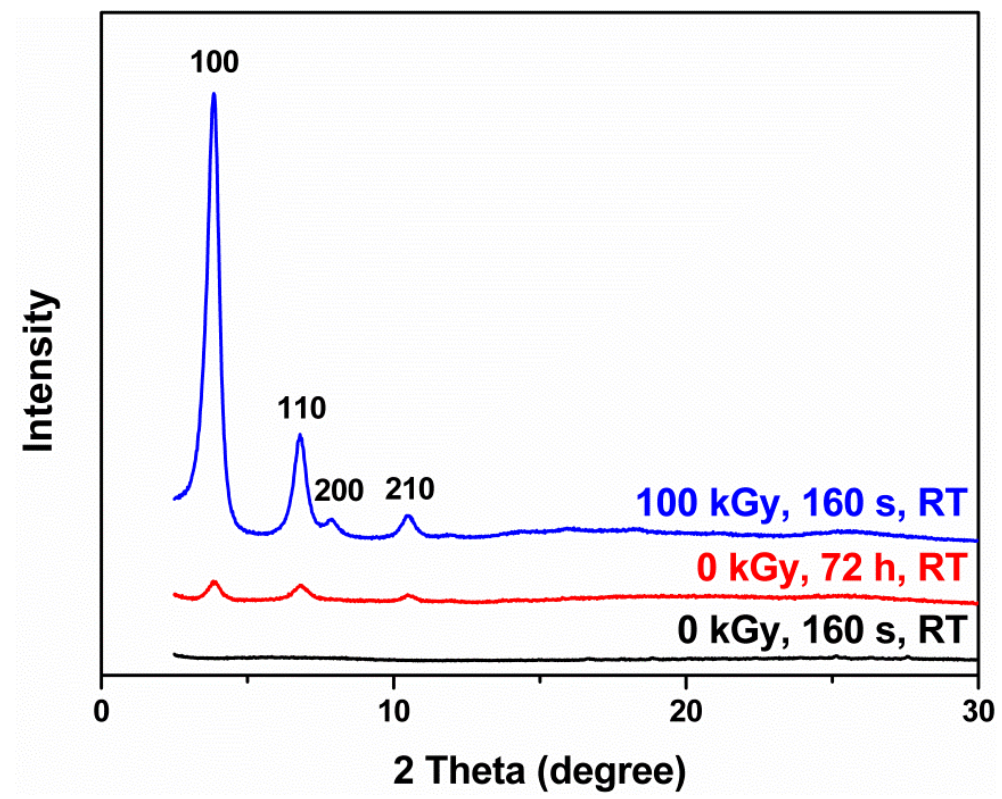

Figure. S11. PXRD patterns of EB-COF-1 synthesized under irradiation and without irradiation. 


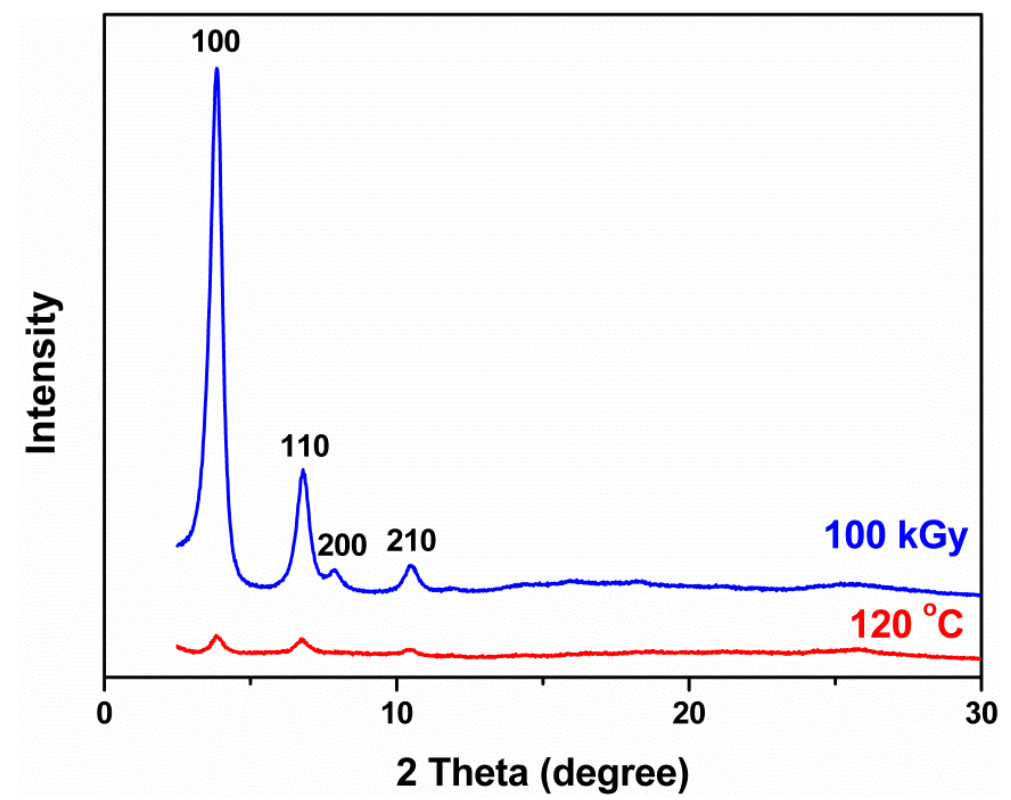

Figure S12. PXRD patterns of EB-COF-1 synthesized by radiation method and conventional solvothermal method.

\section{Section S3. EB-COF-1 synthesized at different absorbed dose: synthesis and characterizations} Synthesis of EB-COF-1 at different absorbed dose

These reactions were performed following the same process of EB-COF-1 at absorbed dose of 100 kGy, except radiated about $8 \mathrm{~s}$ for absorbed dose of $5 \mathrm{kGy}, 480 \mathrm{~s}$ for absorbed dose of $300 \mathrm{kGy}$, and $800 \mathrm{~s}$ for absorbed dose of $500 \mathrm{kGy}$, affording a pale-yellow powder in $90 \%$ isolated yield, a dark yellow powder in $94 \%$ isolated yield, and an orange powder in $92 \%$ isolated yield, respectively.

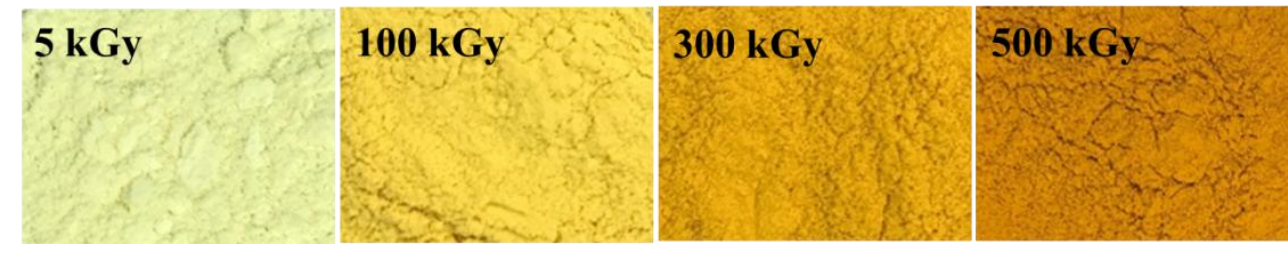

Figure S13. Photos of EB-COF-1 synthesized at different absorbed dose.

Characterizations of EB-COF-1 synthesized at different absorbed dose 


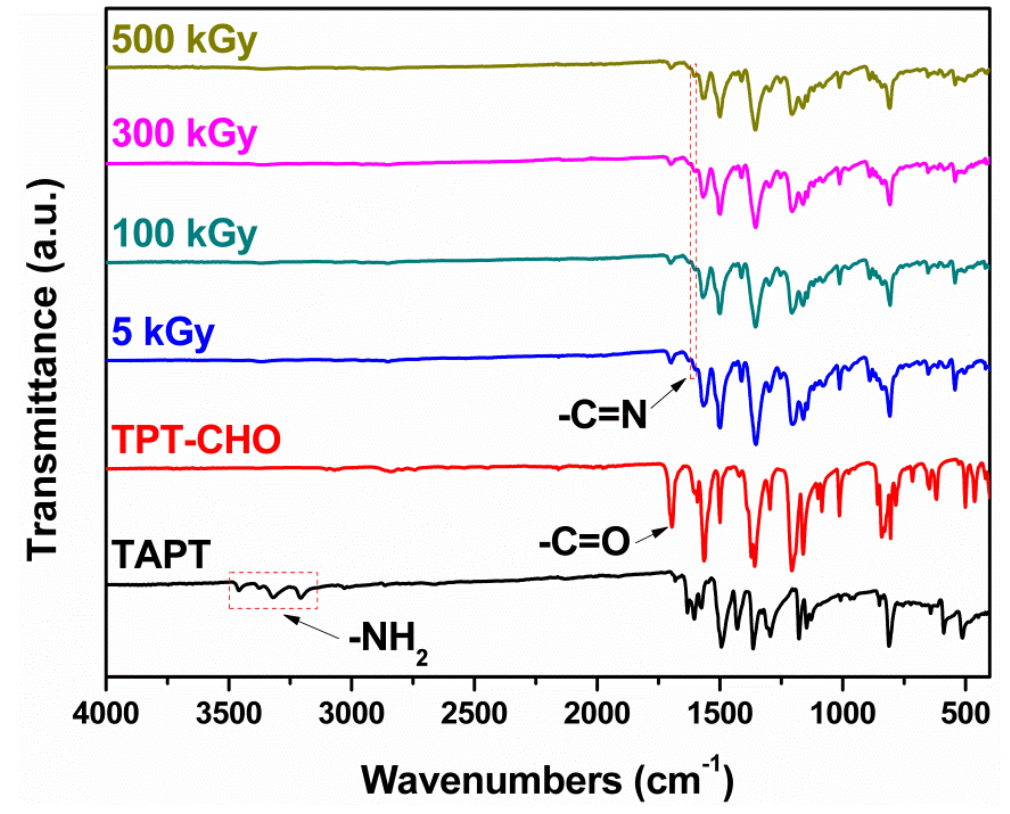

Figure S14. FT-IR spectra for EB-COF-1 synthesized at 5, 100, 300, and $500 \mathrm{kGy}$.

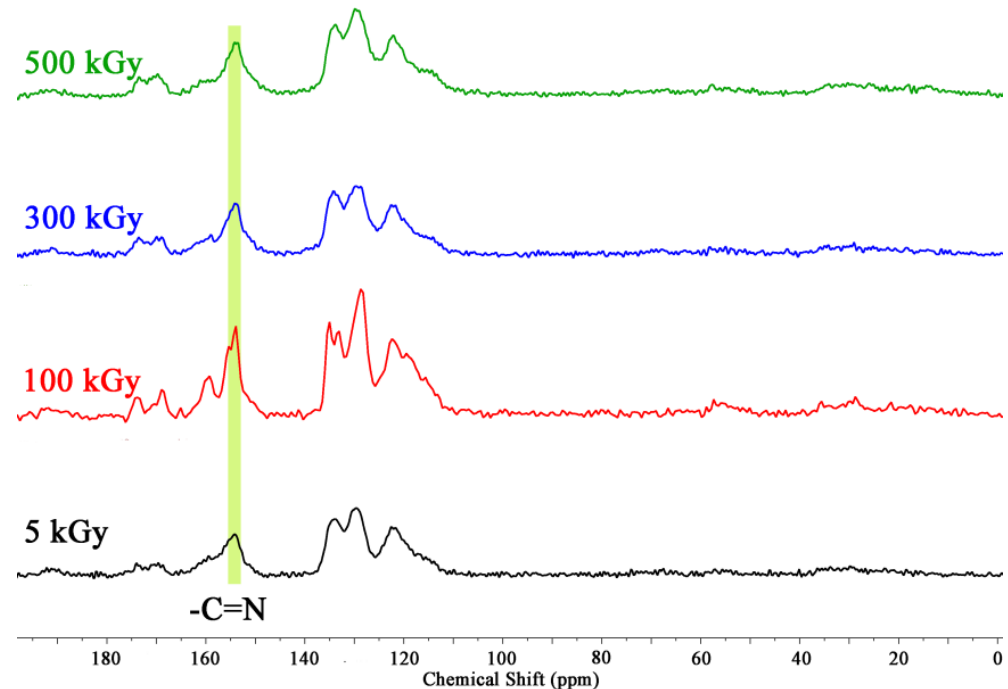

Figure S15. Solid-state ${ }^{13} \mathrm{C}$ NMR spectra for EB-COF-1 synthesized at 5, 100, 300, and $500 \mathrm{kGy}$. 


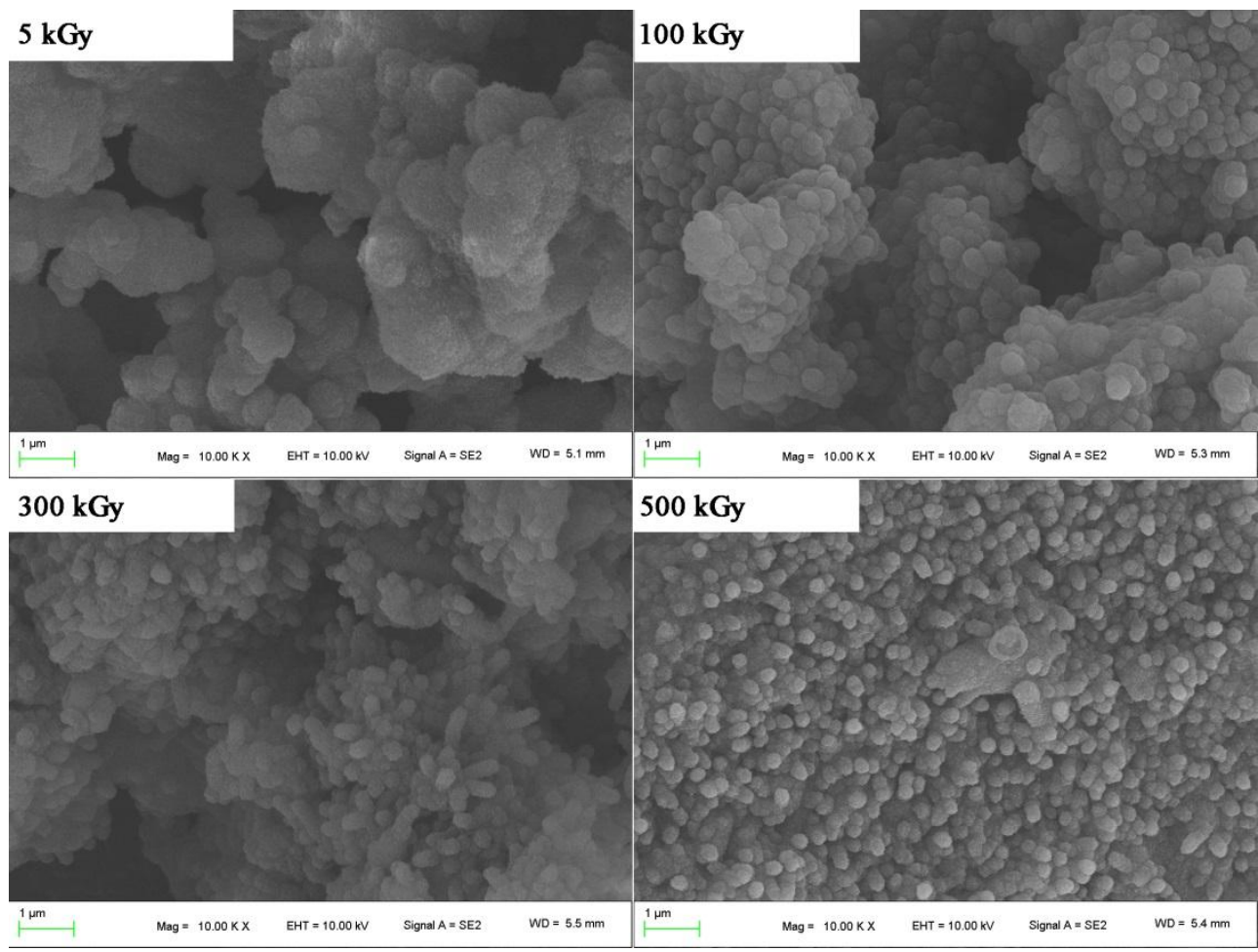

Figure S16. SEM images for EB-COF-1 synthesized at 5, 100, 300, and $500 \mathrm{kGy}$.
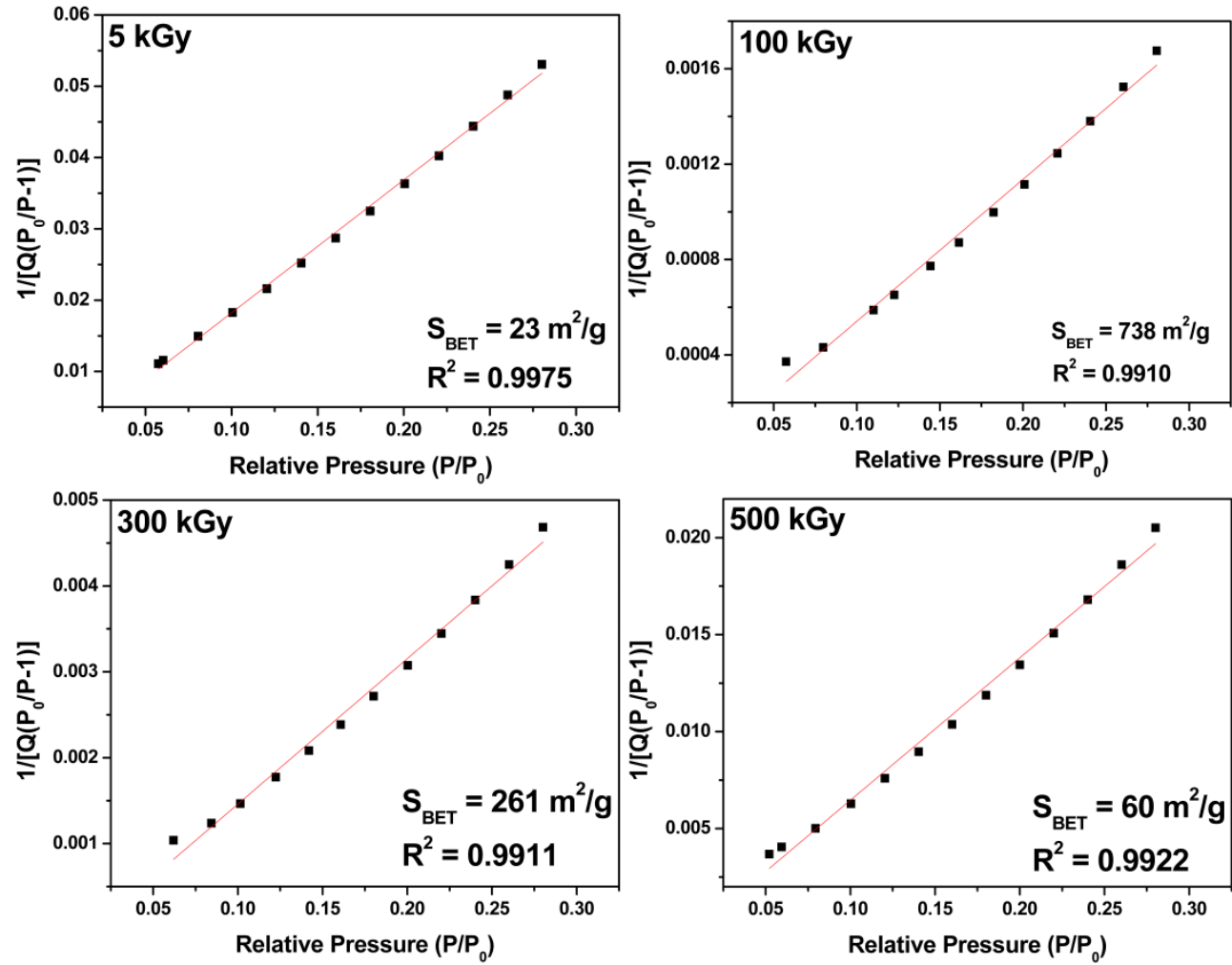

Figure S17. BET plots for EB-COF-1 synthesized at 5, 100, 300, and $500 \mathrm{kGy}$. 

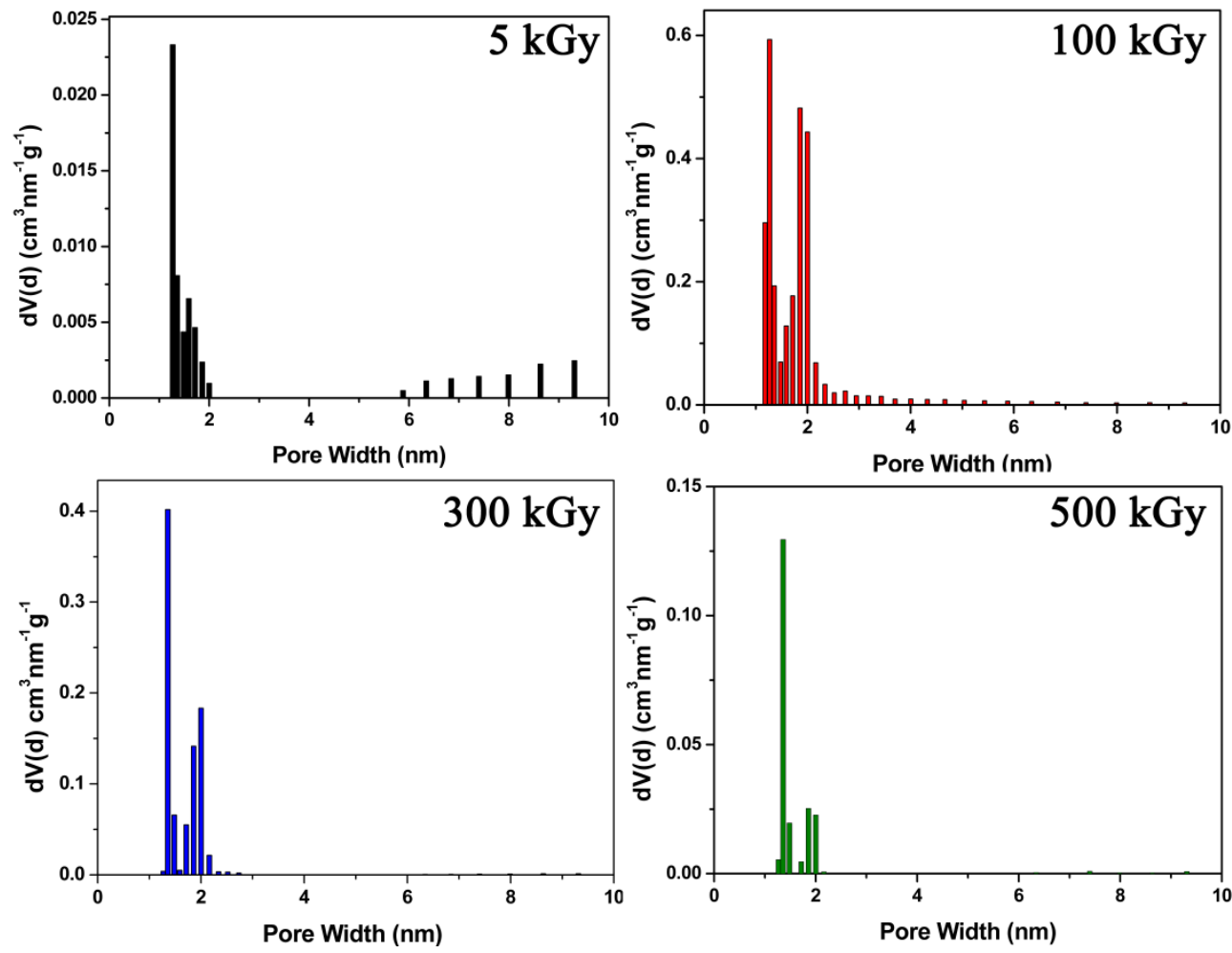

Figure S18. Pore size distribution for EB-COF-1 synthesized at 5, 100, 300, and 500 kGy.
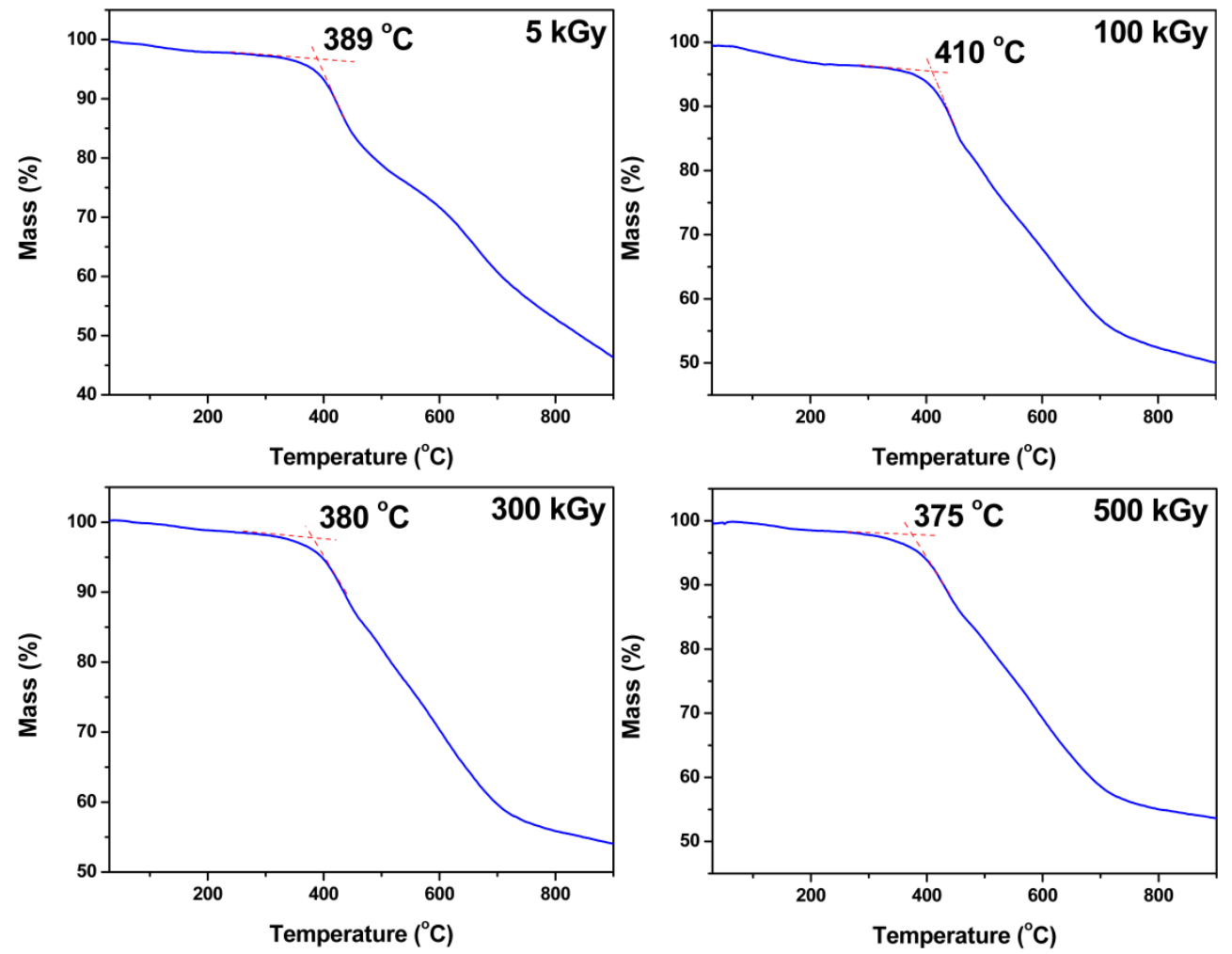

Figure S19. TG curves for EB-COF-1 synthesized at 5, 100, 300, and $500 \mathrm{kGy}$.

Section S4. Theoretical calculations

Computational methods. 
All density functional theory (DFT) simulations were executed using the Gaussian 09 software package. ${ }^{1}$ Geometries were optimized using the M06-2x method ${ }^{2}$ with a 6-31+G (d,p) basis set ${ }^{3}$ and further validated by Hessian evaluations. The description of van der Waals interactions was improved using Grimme's empirical dispersion (GD3) correction, ${ }^{4}$ and the SMD solvation model was used to simulate the binary mixtures of 1-butanol and o-dichlorobenzene in all the calculations. ${ }^{5}$ Transition states with only one imaginary frequency were located using the Berny algorithm at the level of $6-31+\mathrm{G}(\mathrm{d}, \mathrm{p}){ }^{3}$ and intrinsic reaction path (IRC) calculations were performed to verify whether the detected saddle point corresponded to the expected reactant and product paths. Finally, single point calculations were performed at the M06-2x/Def2-TZVP level. ${ }^{6}$

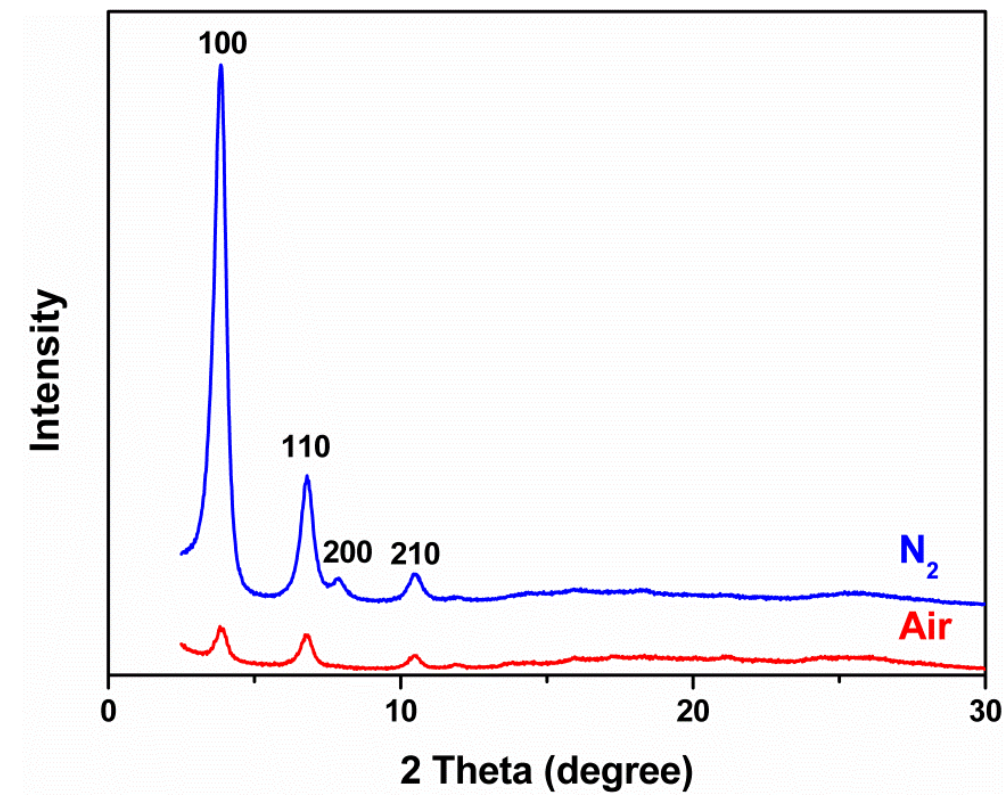

Figure S20. PXRD patterns for EB-COF-1 synthesized under $\mathrm{N}_{2}$ and air atmosphere (with and without $\mathrm{O}_{2}$ as the radical quenching agent).

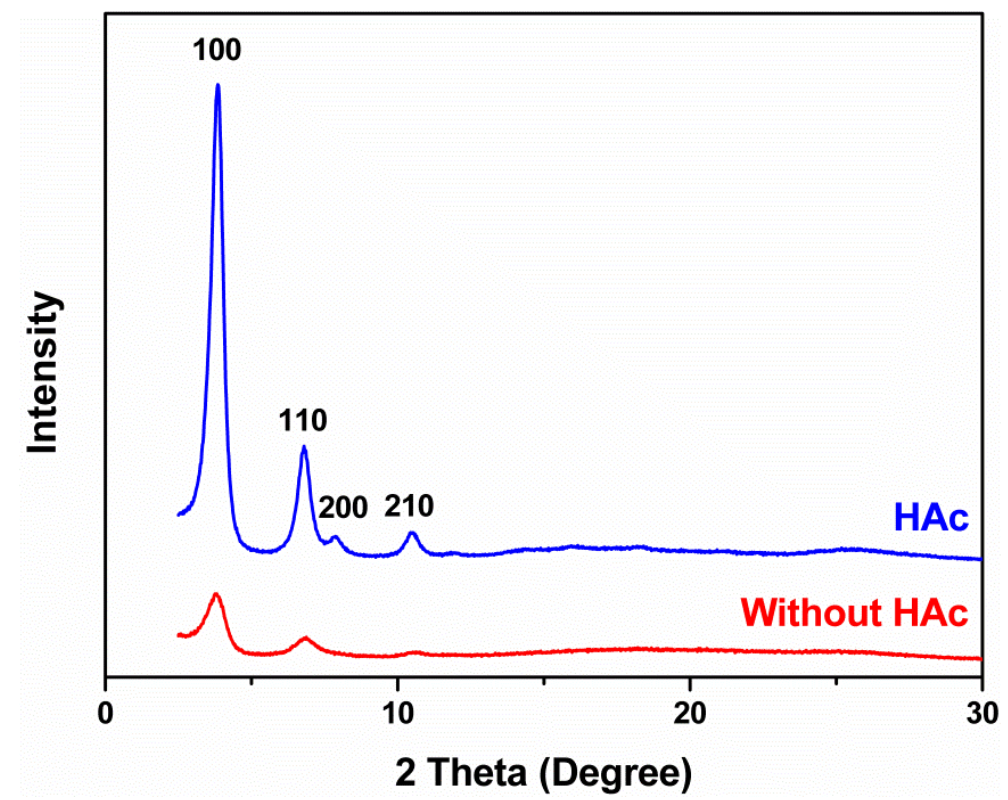

Figure S21. PXRD patterns for EB-COF-1 catalytic synthesized using HAc or without HAc. 


\section{Section S5. General nature for the synthesis of COFs}

The chemical structures and abbreviations of all monomers are listed in Table $\mathbf{S 2}$ in detail. A series of COFs were synthesized by radiation method using the similar process of EB-COF-1 at absorbed dose of $100 \mathrm{kGy}$ except the monomers and solvents. The monomers and as-prepared EB-COFs are shown in Table S3. The PXRD patterns and chemical structures of these EB-COFs are shown in Figure S22-S45.

Table S2. The chemical structures and abbreviations of all monomers.

(n)




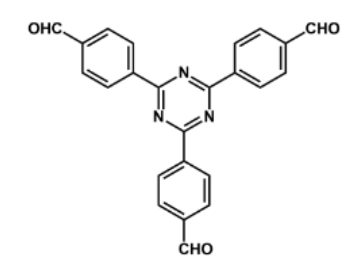

TFPT

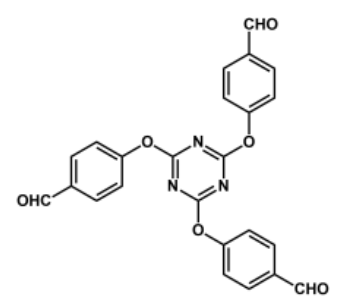

TPT-CHO

Table S3. The monomers and as-prepared EB-COFs.

\begin{tabular}{|c|c|c|c|}
\hline \multicolumn{2}{|c|}{ Reagents } & \multirow{2}{*}{ Products } & \multirow{2}{*}{ Reported/unreported } \\
\hline Monomer 1 & Monomer 2 & & \\
\hline TPT-CHO & TAPT & EB-COF-1 & This work \\
\hline TPT-CHO & $\mathrm{Pa}$ & EB-COF-2 & Reported $^{7}$ \\
\hline TPT-CHO & $\mathrm{BD}$ & EB-COF-3 & Reported $^{8}$ \\
\hline TPT-CHO & $\mathrm{BD}(\mathrm{Me})_{2}$ & EB-COF-4 & This work \\
\hline TPT-CHO & DHBD & EB-COF-5 & Reported $^{8}$ \\
\hline TPT-CHO & $\mathrm{BD}(\mathrm{OMe})_{2}$ & EB-COF-6 & This work \\
\hline TPT-CHO & TAPB & EB-COF-7 & This work \\
\hline TPT-CHO & TPT-NH ${ }_{2}$ & EB-COF-8 & Reported $^{9}$ \\
\hline TPT-NH 2 & TFB & EB-COF-9 & This work \\
\hline TPT-NH 2 & PDA & EB-COF-10 & Reported $^{9}$ \\
\hline TPT-NH & DHTA & EB-COF-11 & Reported $^{10}$ \\
\hline TPT-NH ${ }_{2}$ & DMTA & EB-COF-12 & This work \\
\hline TPT-NH ${ }_{2}$ & BPDA & EB-COF-13 & This work \\
\hline TPT-NH ${ }_{2}$ & 2,2'-BPyDCA & EB-COF-14 & This work \\
\hline TPT-NH ${ }_{2}$ & TFPB & EB-COF-15 & This work \\
\hline TPT-NH ${ }_{2}$ & TFPT & EB-COF-16 & This work \\
\hline TAPB & PDA & EB-COF-17 & Reported $^{11}$ \\
\hline
\end{tabular}




\begin{tabular}{cccc}
\hline TAPB & DHTA & EB-COF-18 & Reported $^{12}$ \\
TAPB & DMTA & EB-COF-19 & Reported $^{13}$ \\
TAPT & DHTA & EB-COF-20 & Reported $^{14}$ \\
TFB & $\mathrm{BD}(\mathrm{Me})_{2}$ & $\mathbf{E B - C O F - 2 1}$ & Reported $^{15}$ \\
TFP & $\mathrm{BD}(\mathrm{Me})_{2}$ & $\mathbf{E B - C O F - 2 2}$ & Reported $^{16}$ \\
TFPB & $\mathrm{BD}(\mathrm{OMe})_{2}$ & $\mathbf{E B - C O F - 2 3}$ & This work $^{16}$ \\
TFPT & $\mathrm{BD}(\mathrm{OMe})_{2}$ & $\mathbf{E B - C O F - 2 4}$ & This work \\
\hline
\end{tabular}

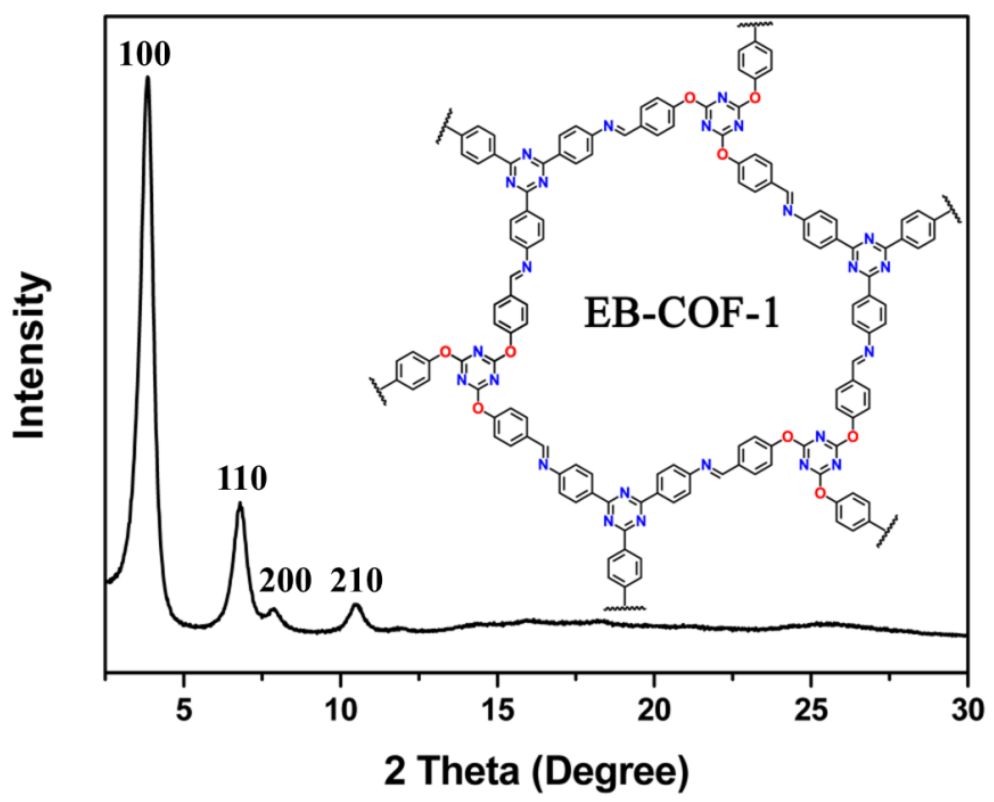

Figure S22. PXRD pattern and chemical structure of EB-COF-1. 


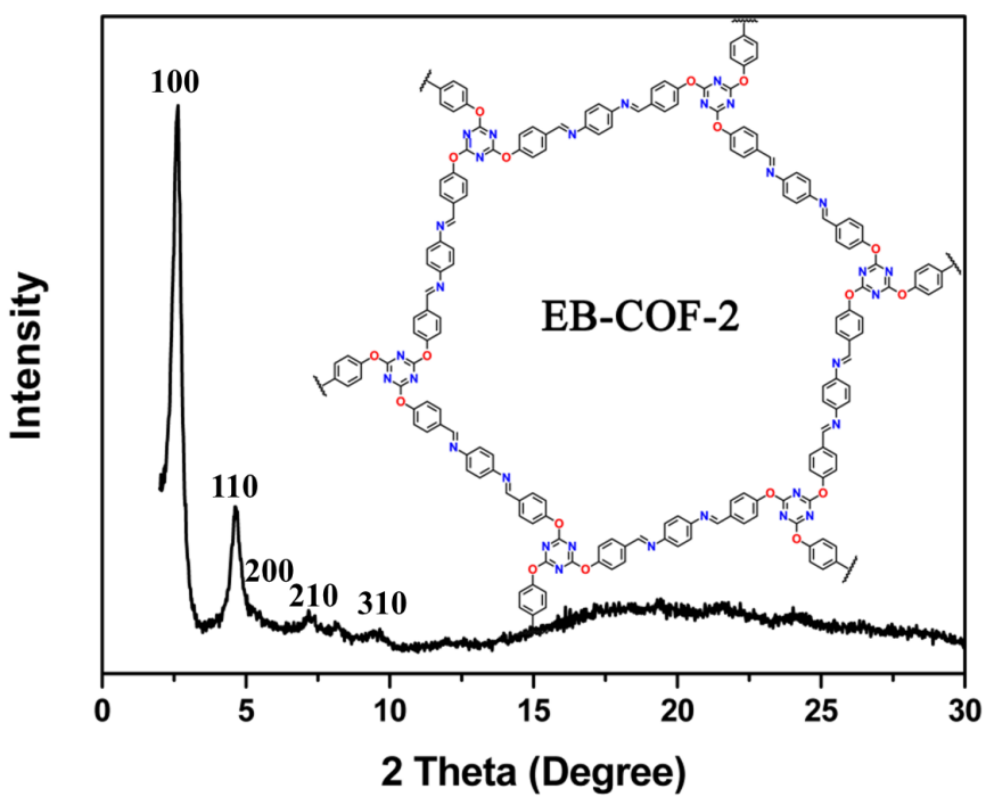

Figure S23. PXRD pattern and chemical structure of EB-COF-2.

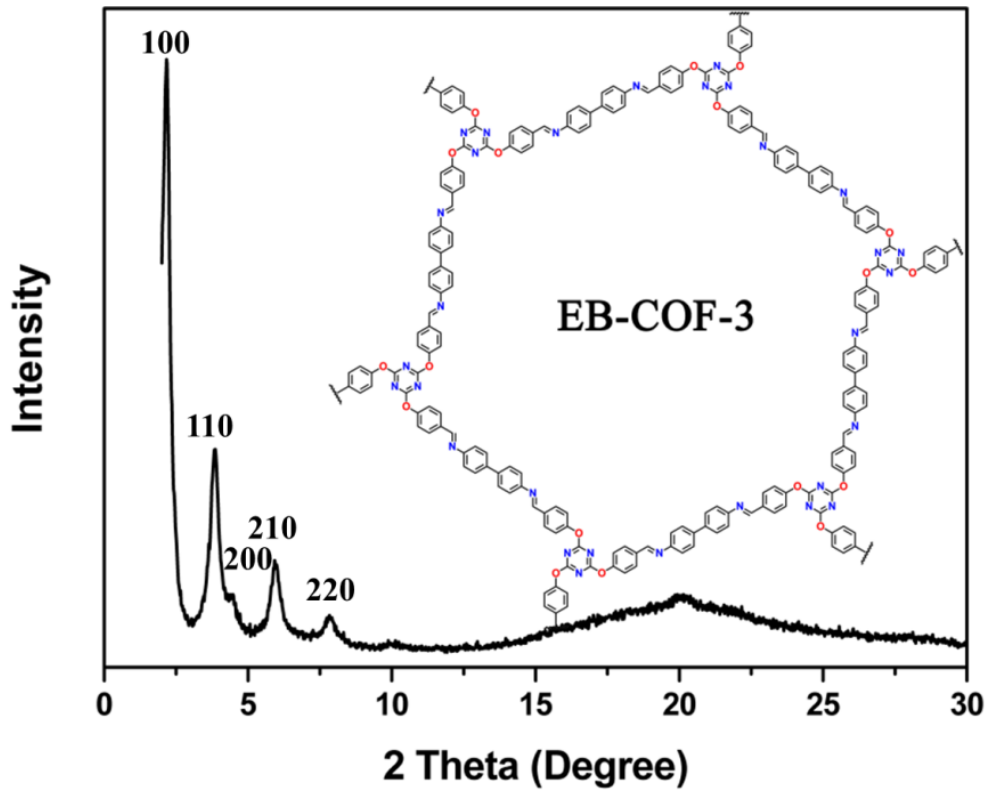

Figure S24. PXRD pattern and chemical structure of EB-COF-3. 


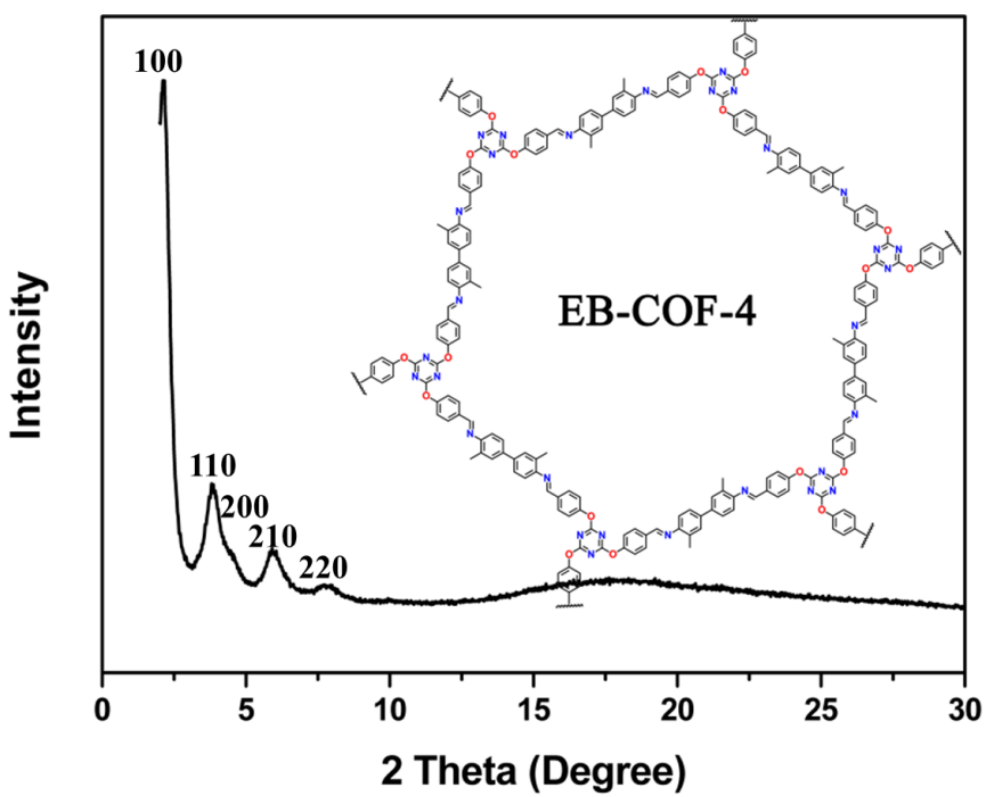

Figure S25. PXRD pattern and chemical structure of EB-COF-4.

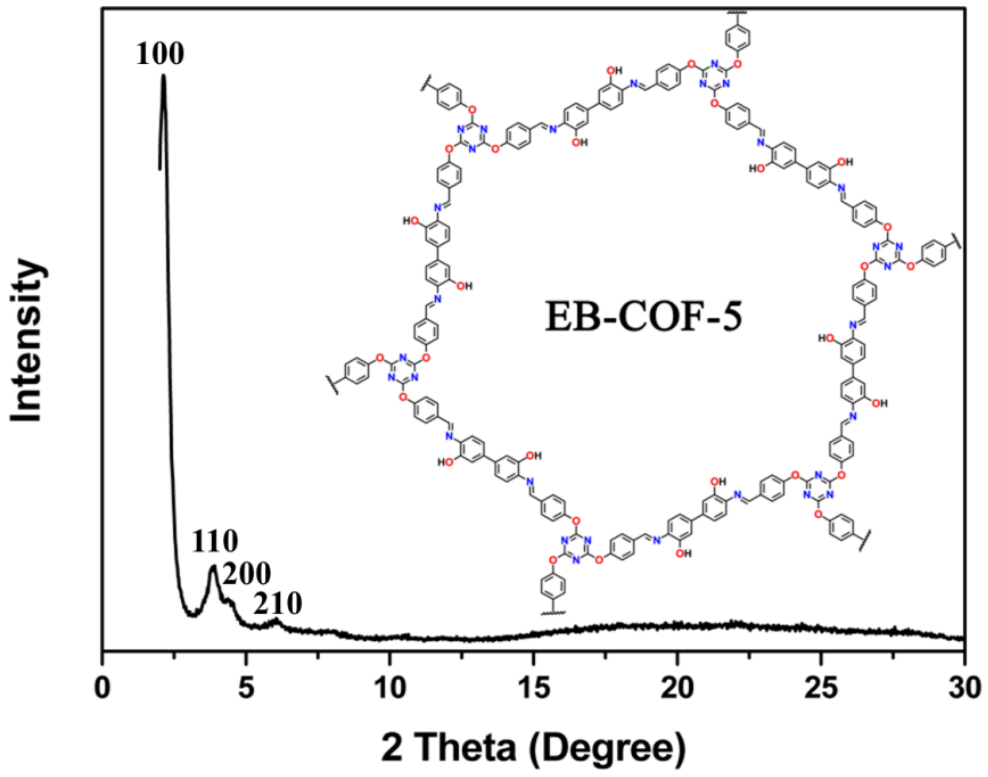

Figure S26. PXRD pattern and chemical structure of EB-COF-5. 


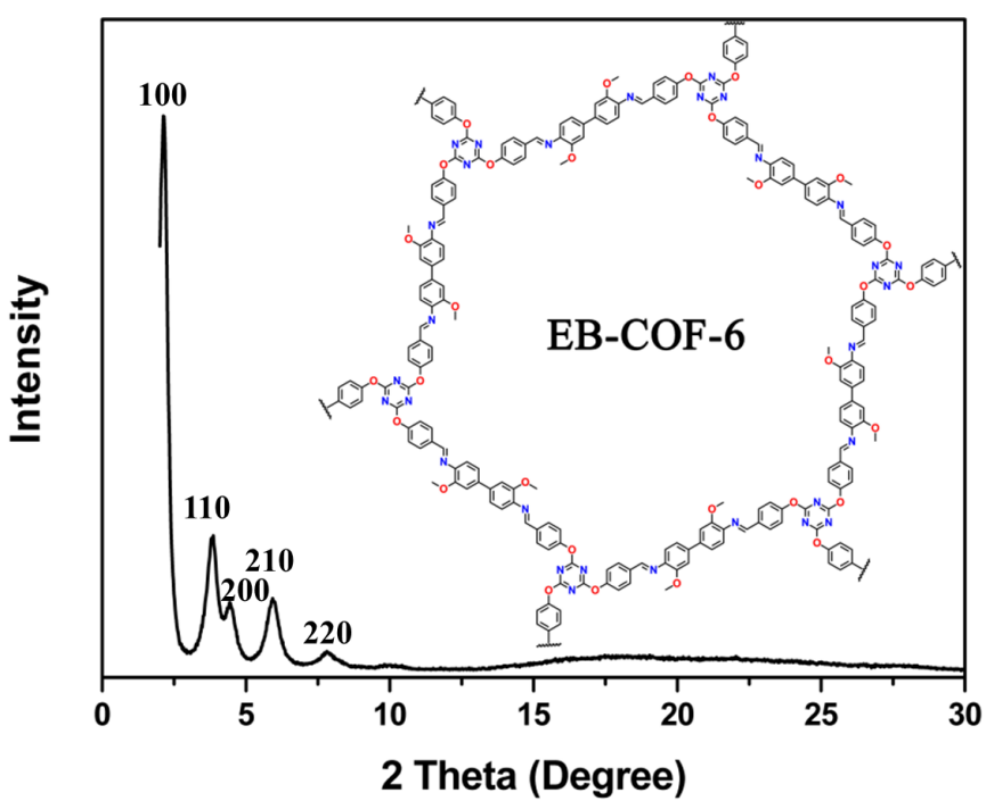

Figure S27. PXRD pattern and chemical structure of EB-COF-6.

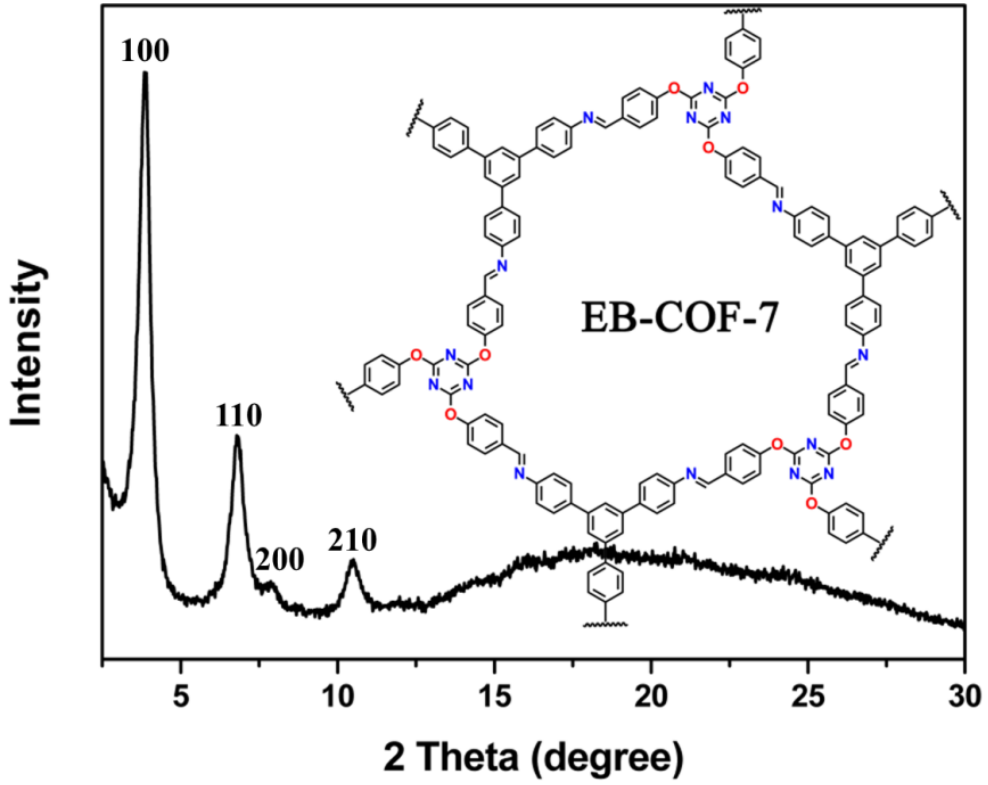

Figure S28. PXRD pattern and chemical structure of EB-COF-7. 


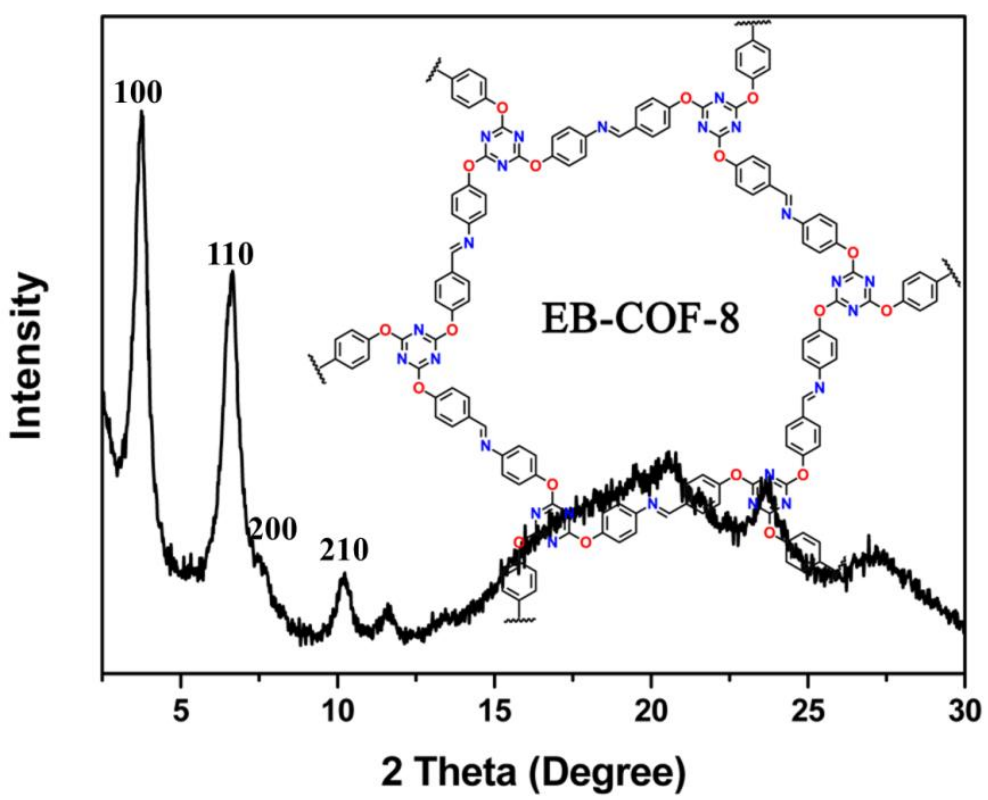

Figure S29. PXRD pattern and chemical structure of EB-COF-8.

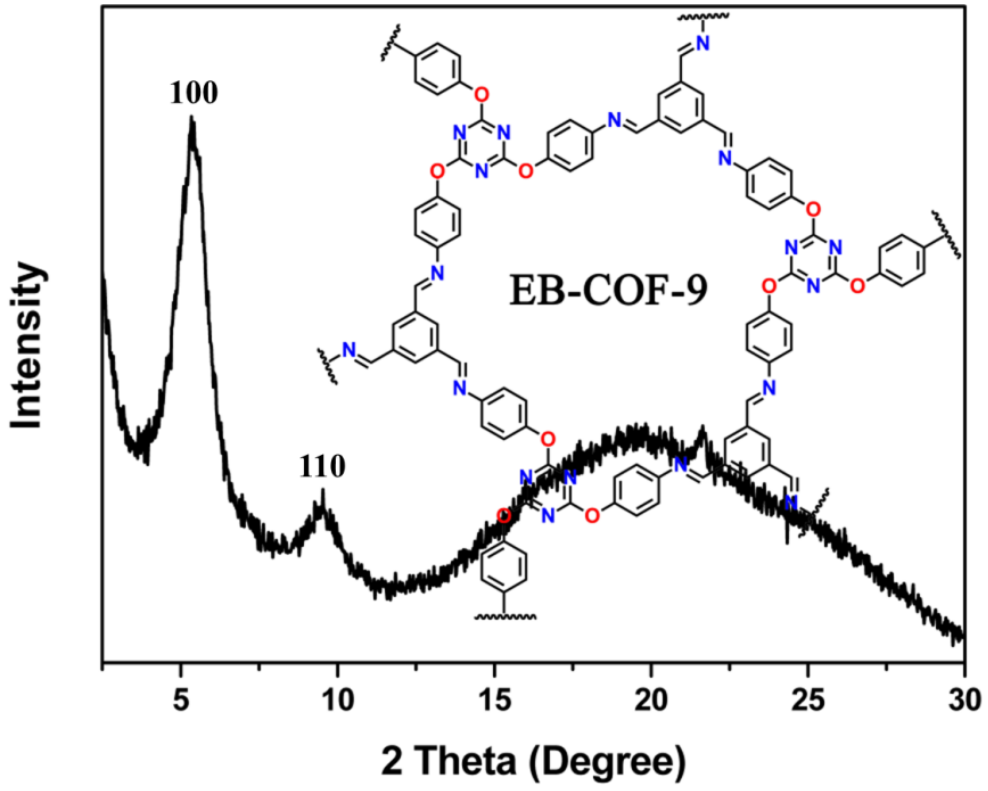

Figure S30. PXRD pattern and chemical structure of EB-COF-9. 


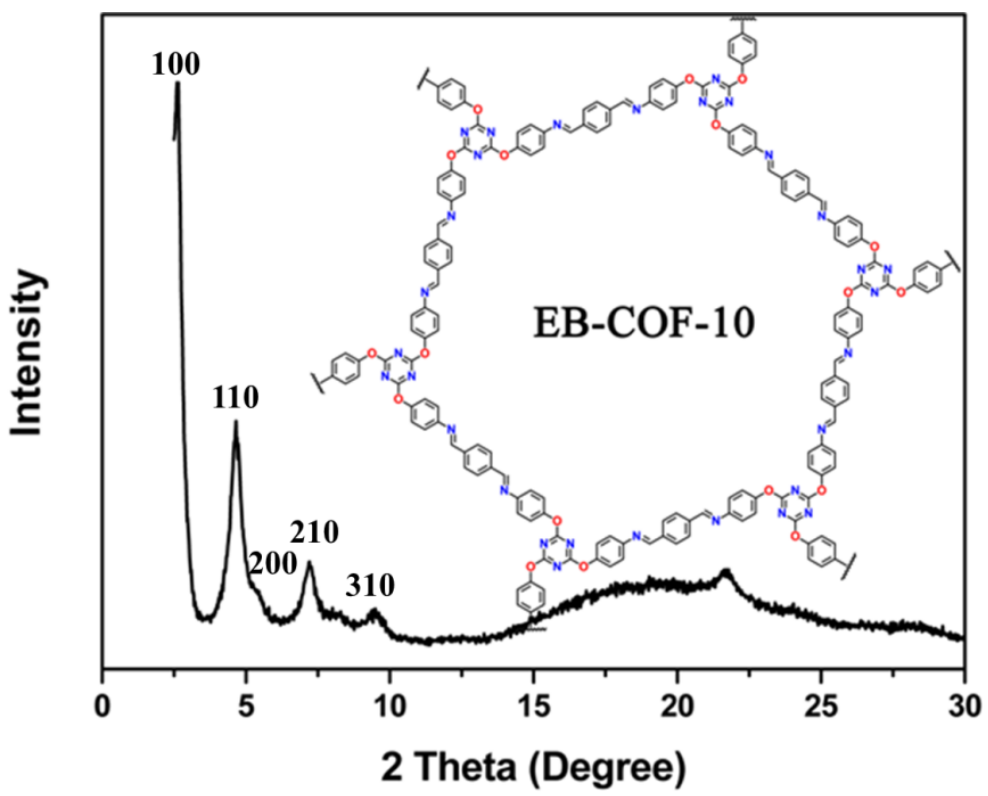

Figure S31. PXRD pattern and chemical structure of EB-COF-10.

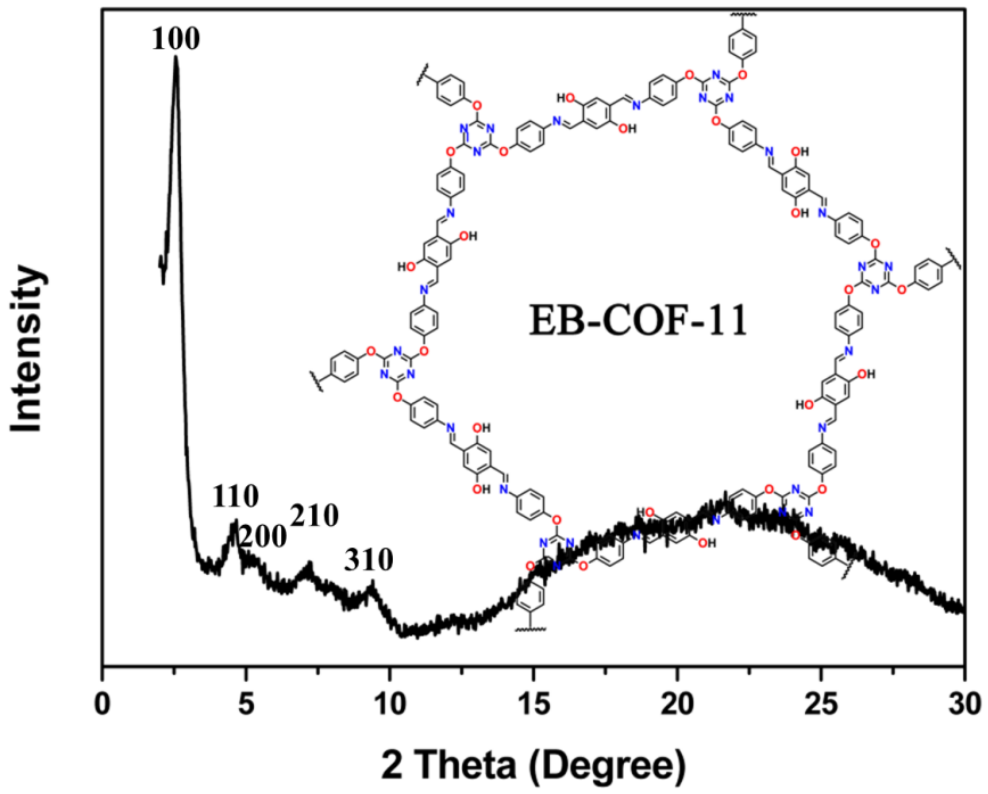

Figure S32. PXRD pattern and chemical structure of EB-COF-11. 


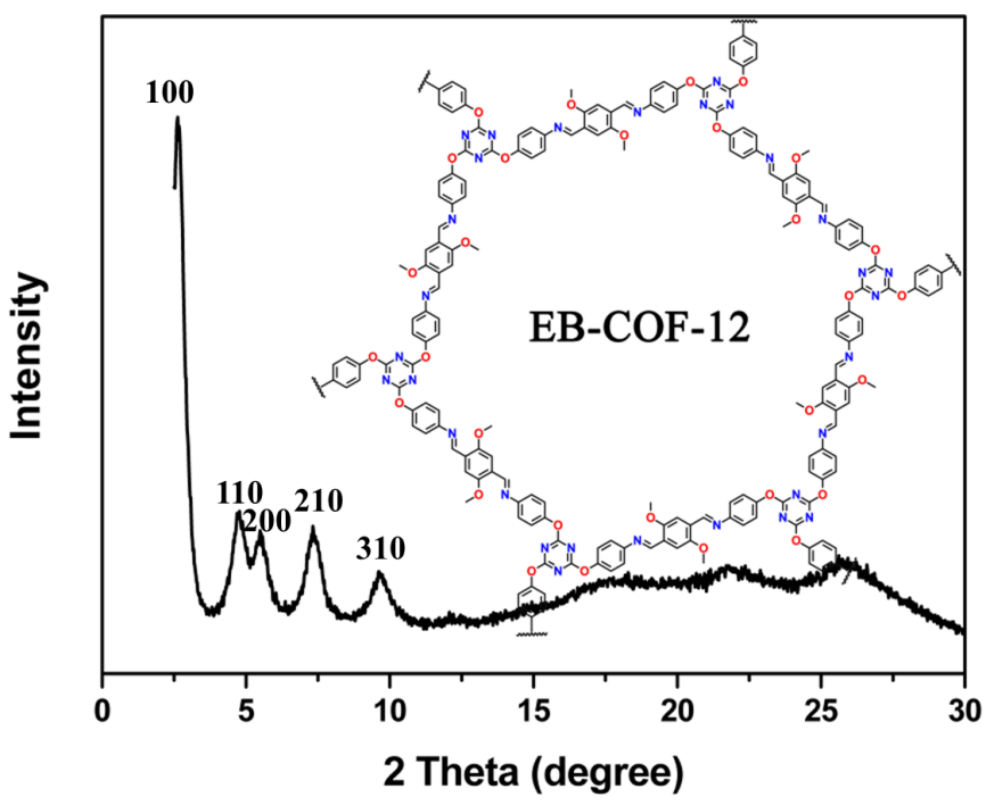

Figure S33. PXRD pattern and chemical structure of EB-COF-12.

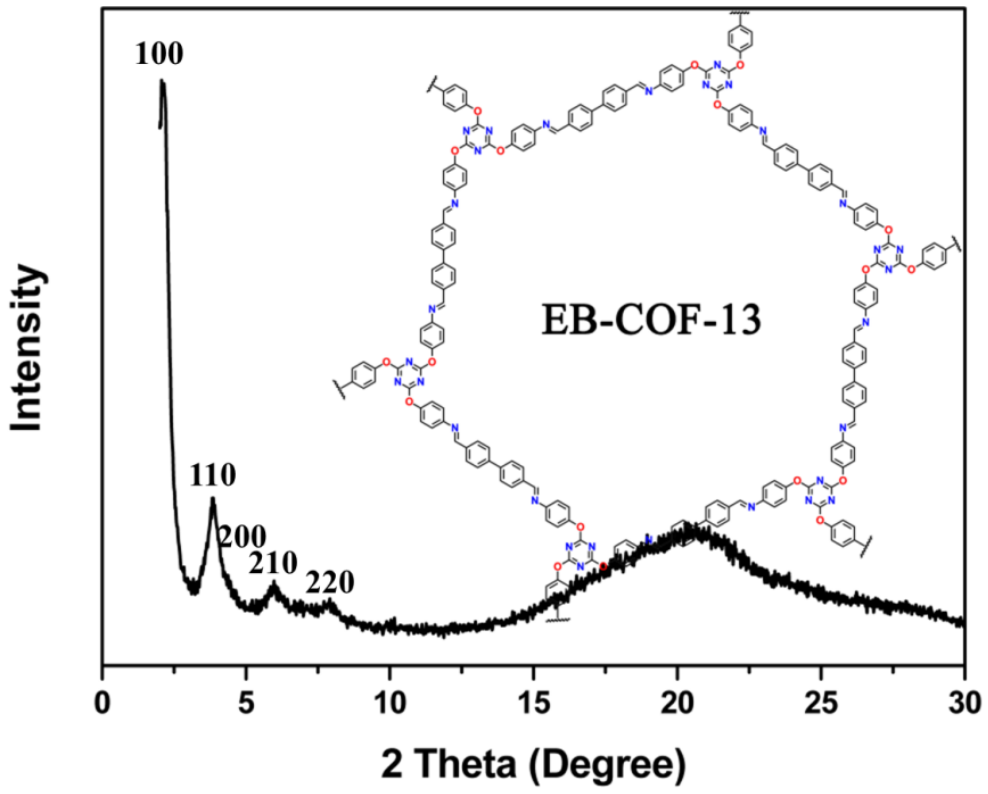

Figure S34. PXRD pattern and chemical structure of EB-COF-13. 


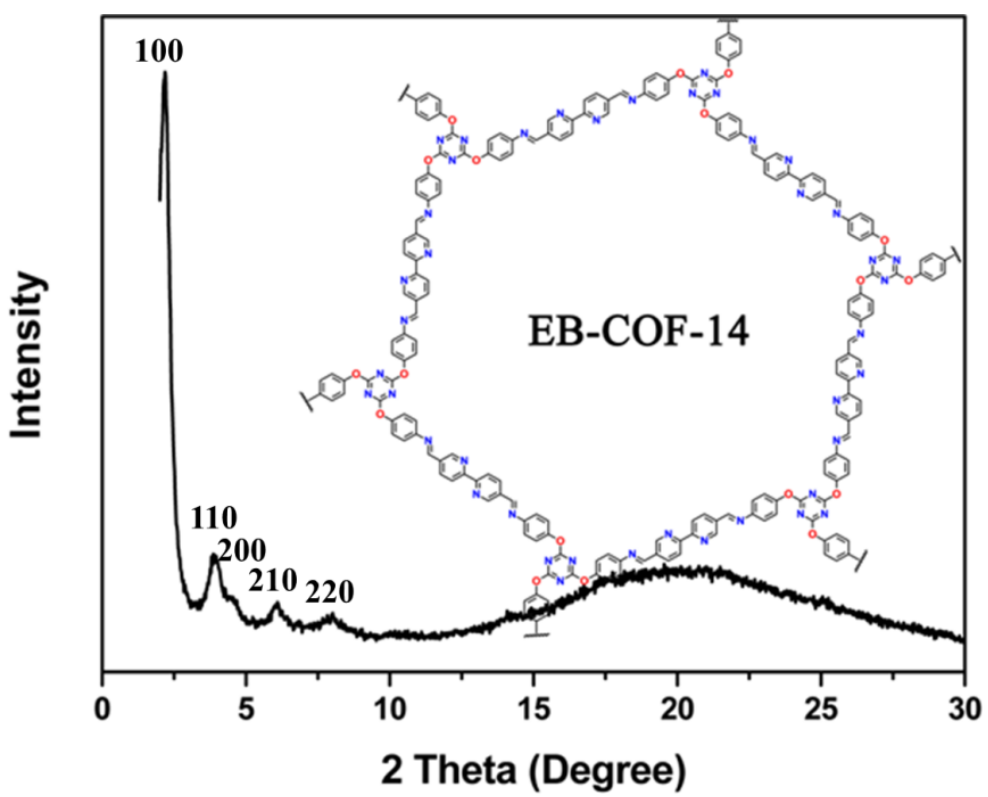

Figure S35. PXRD pattern and chemical structure of EB-COF-14.

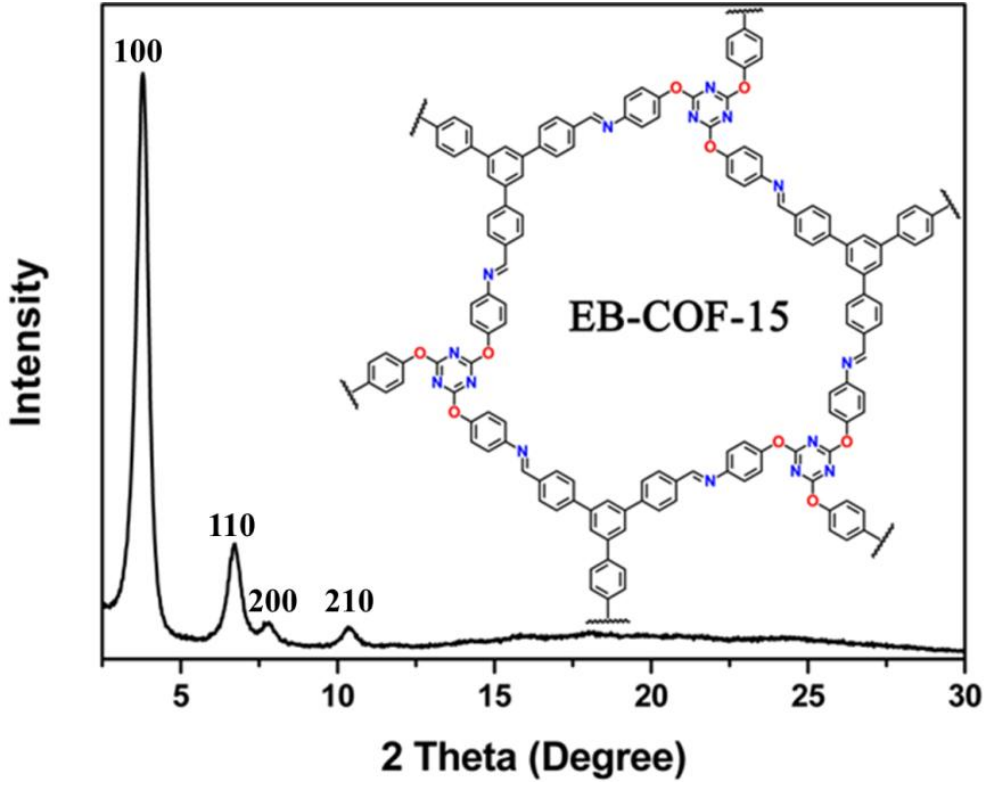

Figure S36. PXRD pattern and chemical structure of EB-COF-15. 


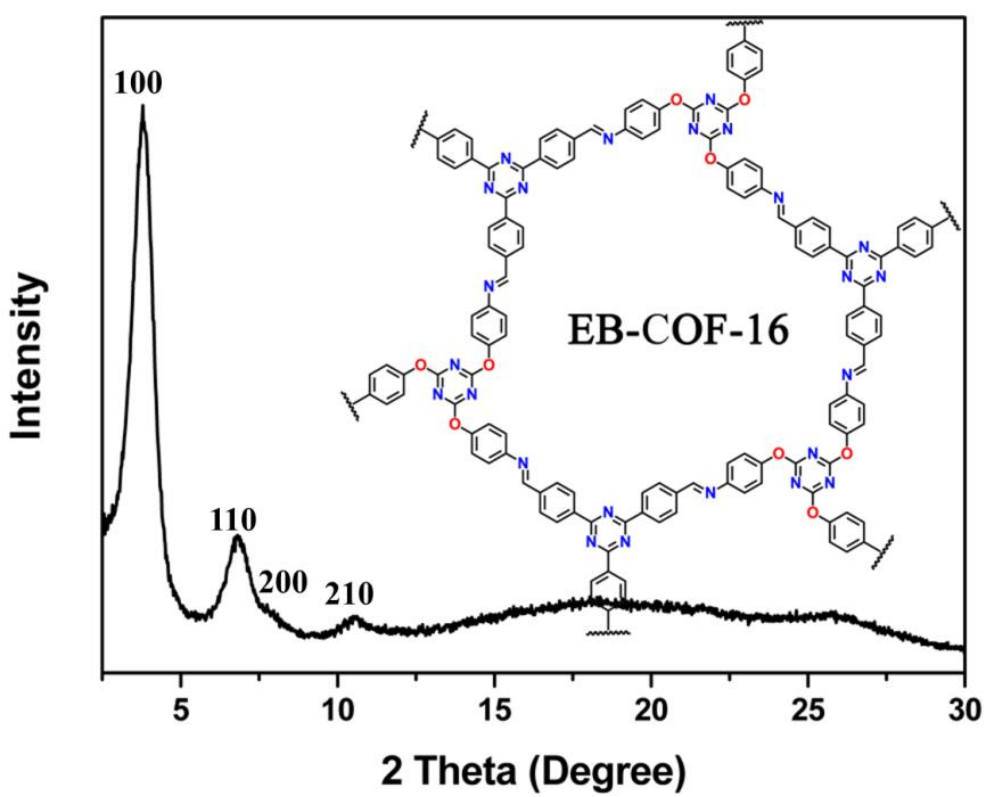

Figure S37. PXRD pattern and chemical structure of EB-COF-16.

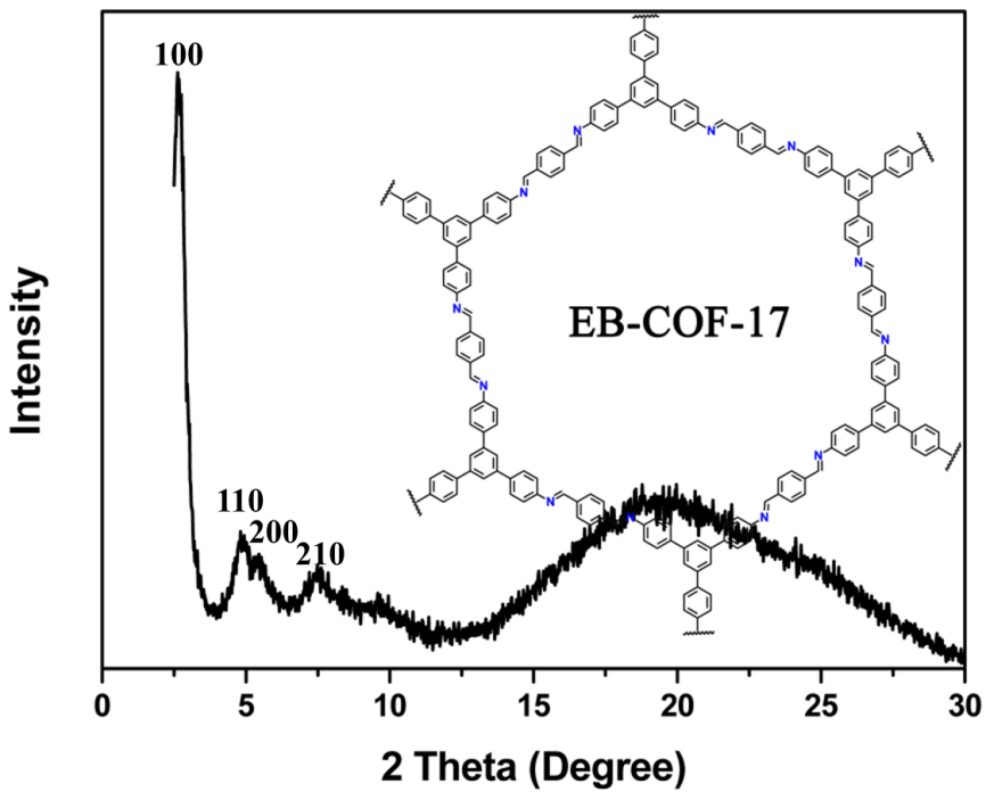

Figure S38. PXRD pattern and chemical structure of EB-COF-17. 


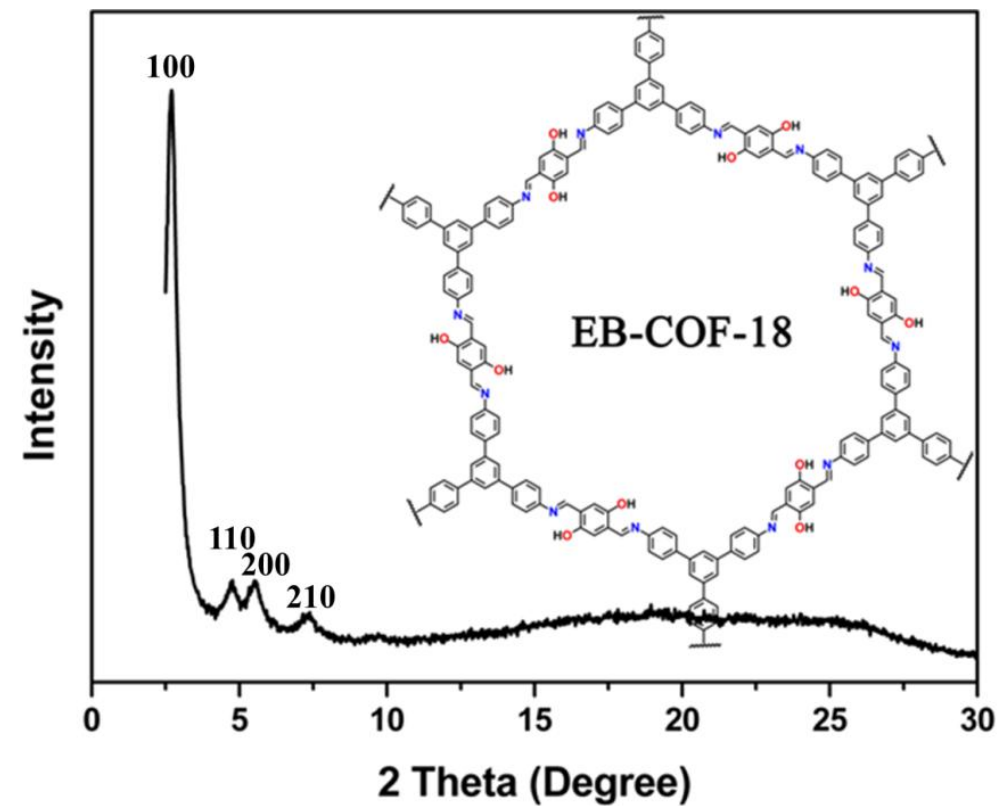

Figure S39. PXRD pattern and chemical structure of EB-COF-18.

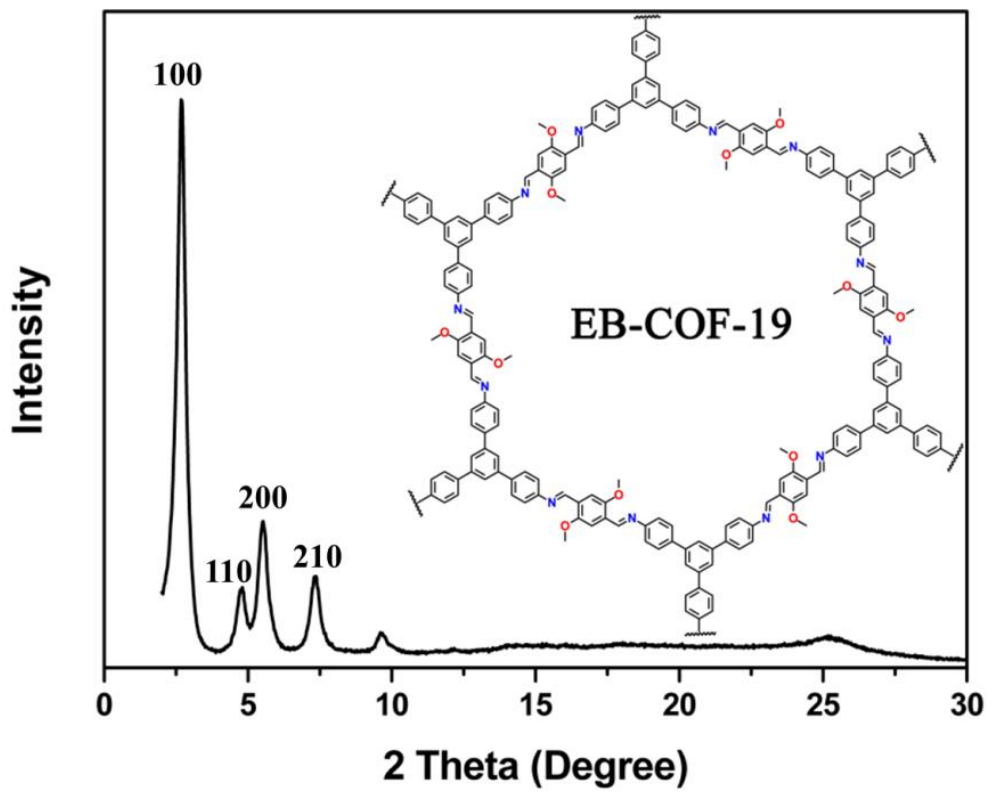

Figure S40. PXRD pattern and chemical structure of EB-COF-19. 


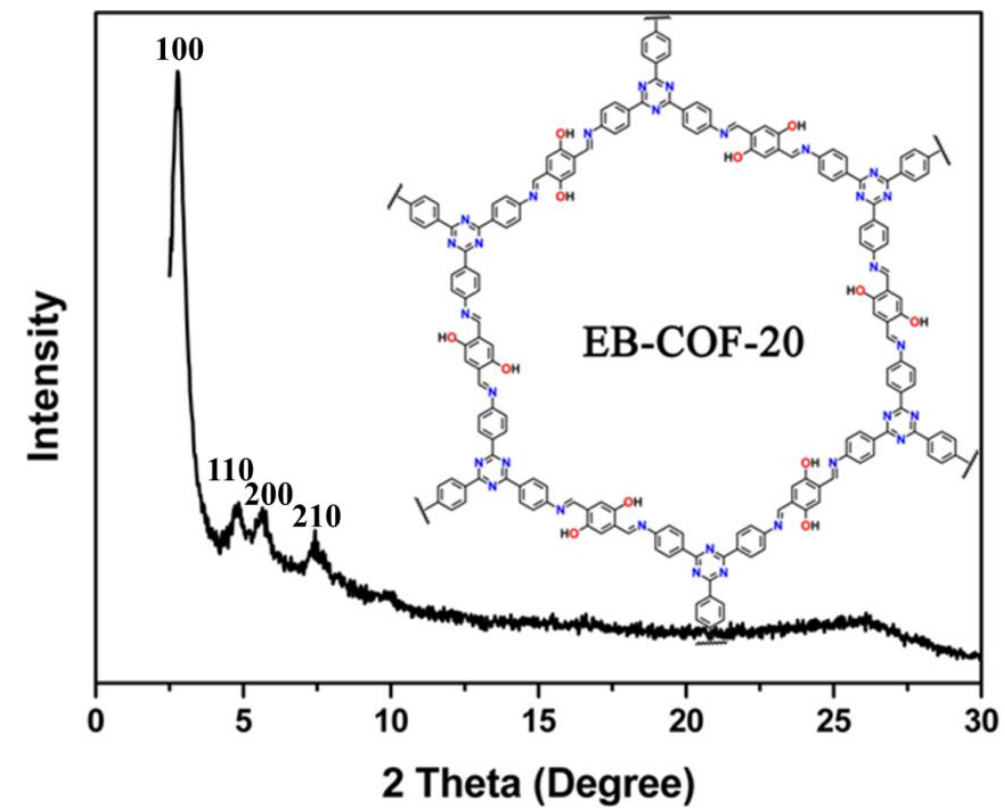

Figure S41. PXRD pattern and chemical structure of EB-COF-20.

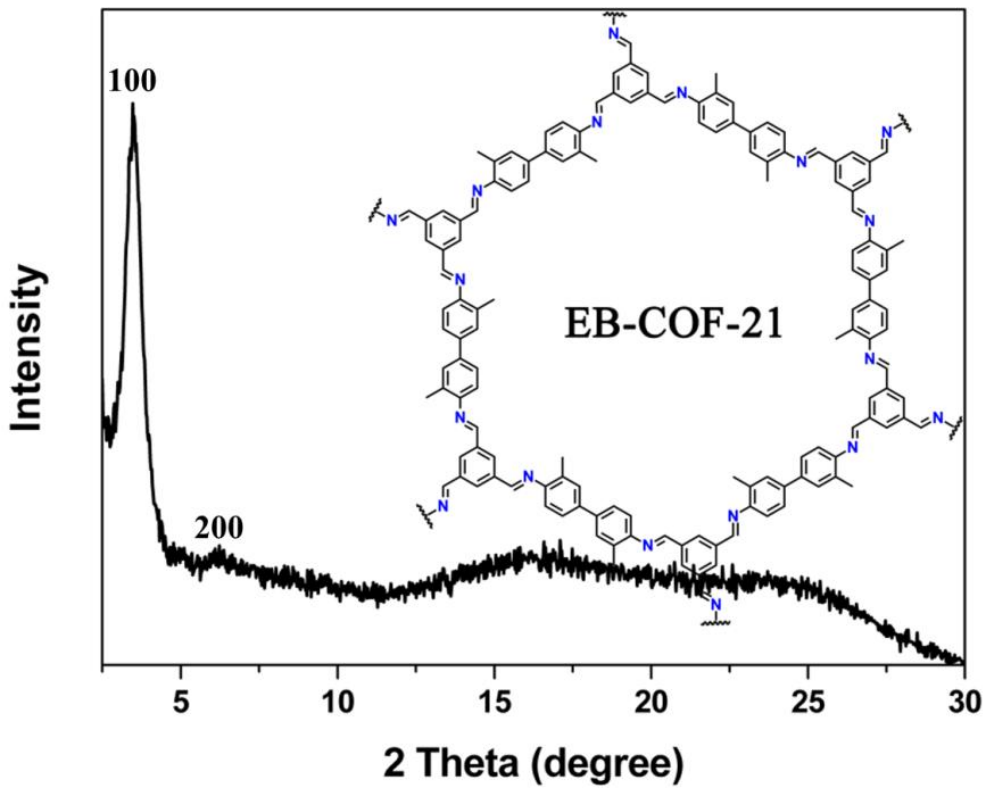

Figure S42. PXRD pattern and chemical structure of EB-COF-21. 


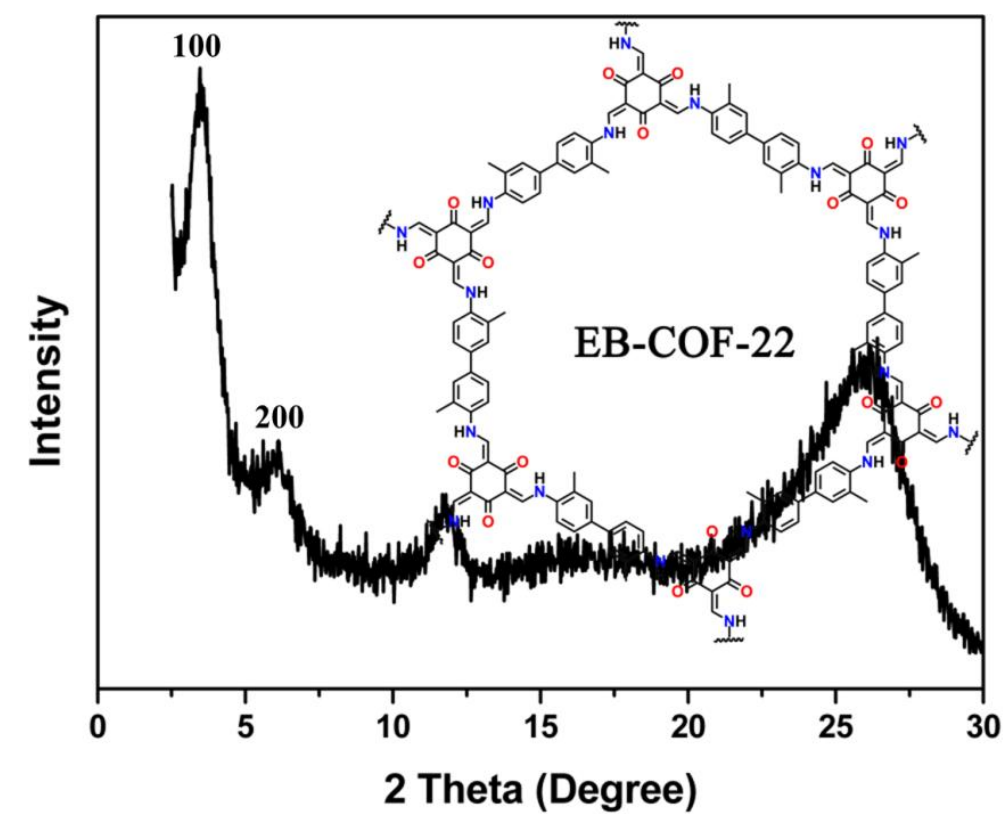

Figure S43. PXRD pattern and chemical structure of EB-COF-22.

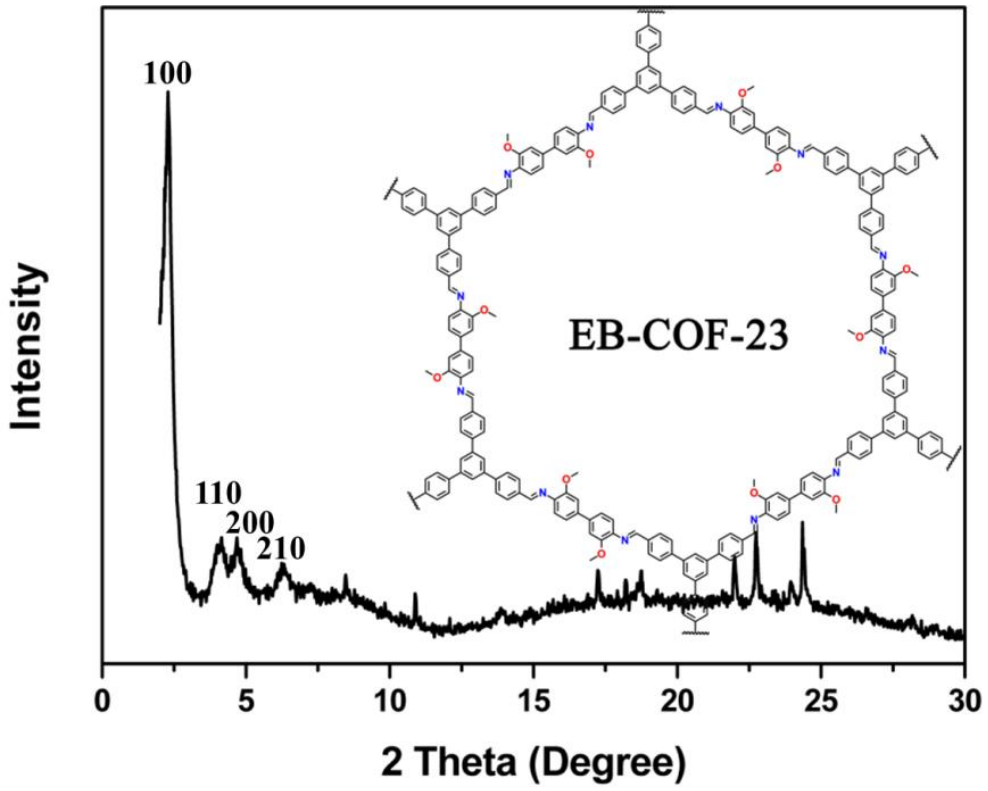

Figure S44. PXRD pattern and chemical structure of EB-COF-23. 


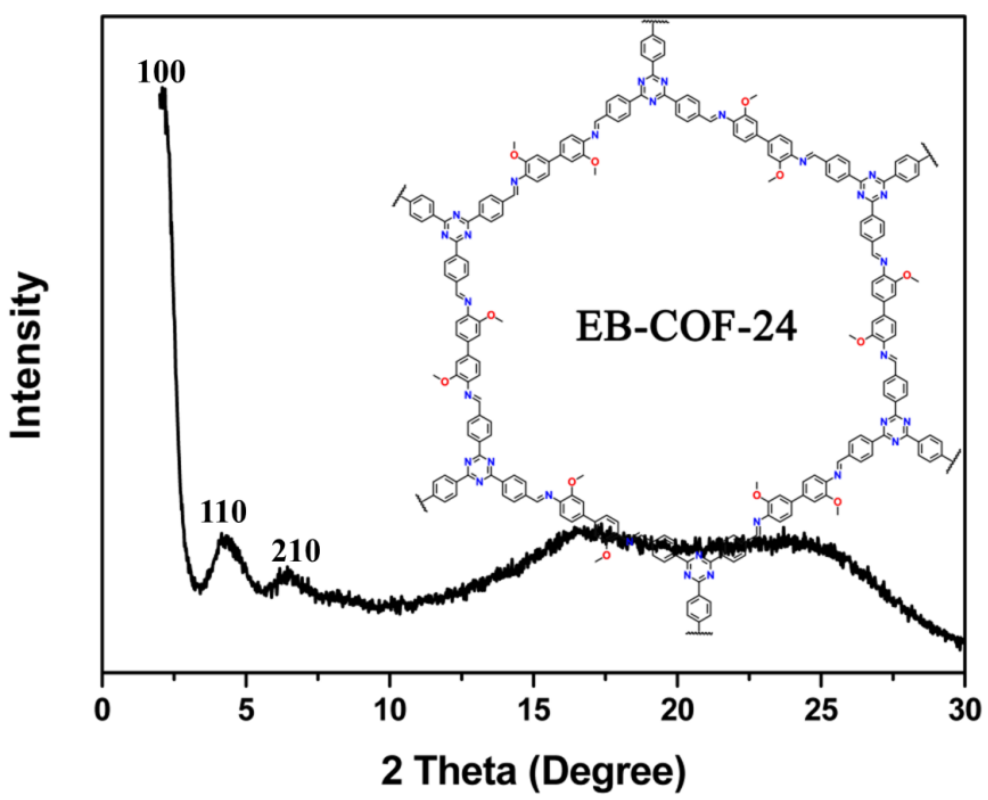

Figure S45. PXRD pattern and chemical structure of EB-COF-24.

\section{Reference}

1. Frisch, M. J.; Trucks, G. W.; Schlegel, H. B.; Scuseria, G. E.; Robb, M. A.; Cheeseman, J. R.; Scalmani, G.; Barone, V.; Petersson, G. A.; Nakatsuji, H.; Li, X.; Caricato, M.; Marenich, A.; Bloino, J.; Janesko, B. G.; Gomperts, R.; Mennucci, B.; Hratchian, H. P.; Ortiz, J. V.; Izmaylov, A. F.; Sonnenberg, J. L.; Williams-Young, D.; Ding, F.; Lipparini, F.; Egidi, F.; Goings, J.; Peng, B.; Petrone, A.; Henderson, T.; Ranasinghe, D.; Zakrzewski, V. G.; Gao, J.; Rega, N.; Zheng, G.; Liang, W.; Hada, M.; Ehara, M.; Toyota, K.; Fukuda, R.; Hasegawa, J.; Ishida, M.; Nakajima, T.; Honda, Y.; Kitao, O.; Nakai, H.; Vreven, T.; Throssell, K.; Montgomery, J. A.; Jr., J. E. P.; Ogliaro, F.; Bearpark, M.; Heyd, J. J.; Brothers, E.; Kudin, K. N.; Staroverov, V. N.; Keith, T.; Kobayashi, R.; Normand, J.; Raghavachari, K.; Rendell, A.; Burant, J. C.; Iyengar, S. S.; Tomasi, J.; Cossi, M.; Millam, J. M.; Klene, M.; Adamo, C.; Cammi, R.; Ochterski, J. W.; Martin, R. L.; Morokuma, K.; Farkas, O.; Foresman, J. B.; D. J. Fox Gaussian 09, Rev. E.01, Wallingford, CT, 2009.

2. Zhao, Y.; Truhlar, D. G., The M06 suite of density functionals for main group thermochemistry, thermochemical kinetics, noncovalent interactions, excited states, and transition elements: two new functionals and systematic testing of four M06-class functionals and 12 other functionals. Theor. Chem. Acc. 2008, 120, 215-241.

3. Hehre, W. J.; Ditchfield, R.; Pople, J. A., Self-consistent molecular-orbital methods .12. further extensions of Gaussian-type basis sets for use in molecular-orbital studies of organic-molecules. $J$. Chem. Phys. 1972, 56, 2257-2261.

4. Grimme, S.; Antony, J.; Ehrlich, S.; Krieg, H., A consistent and accurate ab initio parametrization of density functional dispersion correction (DFT-D) for the 94 elements H-Pu. J. Chem. Phys. 2010, $132,154104$.

5. Tomasi, J.; Mennucci, B.; Cammi, R., Quantum mechanical continuum solvation models. Chem. Rev. 2005, 105, 2999-3094.

6. Schäfer, A.; Huber, C.; Ahlrichs, R., Fully optimized contracted Gaussian basis sets of triple zeta valence quality for atoms Li to Kr. J. Chem. Phys. 1994, 100, 5829-5835.

7. Lin, S.; Hou, Y.; Deng, X.; Wang, H.; Sun, S.; Zhang, X., A triazine-based covalent organic 
framework/palladium hybrid for one-pot silicon-based cross-coupling of silanes and aryl iodides. RSC Adv. 2015, 5, 41017-41024.

8. Guo, X.; Tian, Y.; Zhang, M.; Li, Y.; Wen, R.; Li, X.; Li, X.; Xue, Y.; Ma, L.; Xia, C.; Li, S., Mechanistic insight into hydrogen-bond-controlled crystallinity and adsorption property of covalent organic frameworks from flexible building blocks. Chem. Mater. 2018, 30, 2299-2308.

9. Xu, L.; Ding, S. Y.; Liu, J.; Sun, J.; Wang, W.; Zheng, Q. Y., Highly crystalline covalent organic frameworks from flexible building blocks. Chem. Commun. 2016, 52, 4706-4709.

10. Zhi, Y.; Shao, P.; Feng, X.; Xia, H.; Zhang, Y.; Shi, Z.; Mu, Y.; Liu, X., Covalent organic frameworks: efficient, metal-free, heterogeneous organocatalysts for chemical fixation of $\mathrm{CO}_{2}$ under mild conditions. J.Mater. Chem. A 2018, 6, 374-382.

11. Smith, B. J.; Overholts, A. C.; Hwang, N.; Dichtel, W. R., Insight into the crystallization of amorphous imine-linked polymer networks to 2D covalent organic frameworks. Chem. Commun. 2016, 52, 3690-3693.

12. Kandambeth, S.; Venkatesh, V.; Shinde, D. B.; Kumari, S.; Halder, A.; Verma, S.; Banerjee, R., Self-templated chemically stable hollow spherical covalent organic framework. Nat. Commun. 2015, 6, 6786

13. Xu, H.; Gao, J.; Jiang, D., Stable, crystalline, porous, covalent organic frameworks as a platform for chiral organocatalysts. Nat. Chem. 2015, 7, 905-912.

14. Xu, Q.; Tang, Y.; Zhang, X.; Oshima, Y.; Chen, Q.; Jiang, D., Template conversion of covalent organic frameworks into $2 \mathrm{D}$ conducting nanocarbons for catalyzing oxygen reduction reaction. Adv. Mater. 2018, 30, 1706330.

15. Xu, L.; Zhou, X.; Yu, Y.; Tian, W. Q.; Ma, J.; Lei, S., Surface-confined crystalline two-dimensional covalent organic frameworks via on-surface schiff-base coupling. ACS Nano 2013, 7, 8066-8073.

16. Chandra, S.; Kandambeth, S.; Biswal, B. P.; Lukose, B.; Kunjir, S. M.; Chaudhary, M.; Babarao, R.; Heine, T.; Banerjee, R., Chemically stable multilayered covalent organic nanosheets from covalent organic frameworks via mechanical delamination. J. Am. Chem. Soc. 2013, 135, 17853-17861. 